IUCrJ

ISSN 2052-2525

BIOLOGY|MEDICINE

Received 24 September 2018

Accepted 20 February 2019

Edited by M. Takata, SPring-8, Japan

₹ These authors contributed equally

Keywords: third-generation synchrotrons; pinkbeam serial crystallography; injector-based serial crystallography; structure determination; membrane proteins; protein structures; X-ray crystallography; structural biology.

PDB references: proteinase $\mathrm{K}, 6 \mathrm{mh} 6$; human $\mathrm{A}_{2 \mathrm{~A}}$ adenosine receptor, $6 \mathrm{mh} 8$

Supporting information: this article has supporting information at www.iucrj.org

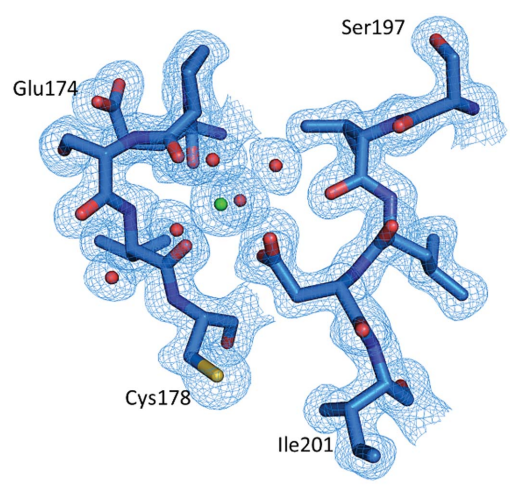

OPEN $\odot$ ACCESS

\section{High-viscosity injector-based pink-beam serial crystallography of microcrystals at a synchrotron radiation source}

\author{
Jose M. Martin-Garcia, ${ }^{a, b} \neq$ Lan Zhu, ${ }^{a, b} \neq$ Derek Mendez, ${ }^{a, c}$ Ming-Yue Lee, ${ }^{a, b}$ Eugene \\ Chun, ${ }^{a, b}$ Chufeng Li, ${ }^{a, c}$ Hao Hu, ${ }^{c}$ Ganesh Subramanian, ${ }^{a, c}$ David Kissick, ${ }^{d}$ Craig \\ Ogata, ${ }^{\mathrm{d}}$ Robert Henning, ${ }^{\mathrm{e}}$ Andrii Ishchenko, ${ }^{\mathrm{f}}$ Zachary Dobson, ${ }^{\mathrm{a}, \mathrm{b}}$ Shangji Zhang, ${ }^{\mathrm{a}, \mathrm{b}}$ \\ Uwe Weierstall, ${ }^{\mathrm{a}, \mathrm{c}}$ John C. H. Spence, ${ }^{\mathrm{a}, \mathrm{c}}$ Petra Fromme, ${ }^{\mathrm{a}, \mathrm{b}}$ Nadia A. Zatsepin, ${ }^{\mathrm{a}, \mathrm{c}}$ \\ Robert F. Fischetti, ${ }^{d}$ Vadim Cherezov ${ }^{f *}$ and Wei Liu ${ }^{a, b *}$
}

\footnotetext{
aBiodesign Center for Applied Structural Discovery, Biodesign Institute, Arizona State University, 727 East Tyler Street Tempe, AZ 85287, USA, 'b School of Molecular Sciences, Arizona State University, 551 East University Drive, Tempe, AZ 85287, USA, ' Department of Physics, Arizona State University, 550 East Tyler Drive, Tempe, AZ 85287, USA, dAdvanced Photon Source, Argonne National Laboratory, 9700 South Cass Ave, Lemont, IL 90439, USA, ${ }^{\mathbf{e}}$ Center for Advanced Radiation Sources, The University of Chicago, Argonne National Laboratory, 9700 South Cass Ave, Lemont, IL 90439, USA, and 'Department of Chemistry, Bridge Institute, University of Southern California, 1002 Childs Way, Los Angeles, CA 90089, USA. *Correspondence e-mail: cherezov@usc.edu,w.liu@asu.edu
}

Since the first successful serial crystallography (SX) experiment at a synchrotron radiation source, the popularity of this approach has continued to grow showing that third-generation synchrotrons can be viable alternatives to scarce X-ray free-electron laser sources. Synchrotron radiation flux may be increased $\sim 100$ times by a moderate increase in the bandwidth ('pink beam' conditions) at some cost to data analysis complexity. Here, we report the first high-viscosity injectorbased pink-beam SX experiments. The structures of proteinase $K(P K)$ and $A_{2 A}$ adenosine receptor $\left(\mathrm{A}_{2 \mathrm{~A}} \mathrm{AR}\right)$ were determined to resolutions of 1.8 and $4.2 \AA$ using 4 and 24 consecutive 100 ps X-ray pulse exposures, respectively. Strong PK data were processed using existing Laue approaches, while weaker $\mathrm{A}_{2 \mathrm{~A}} \mathrm{AR}$ data required an alternative data-processing strategy. This demonstration of the feasibility presents new opportunities for time-resolved experiments with microcrystals to study structural changes in real time at pink-beam synchrotron beamlines worldwide.

\section{Introduction}

In recent years, the field of structural biology has experienced numerous technological breakthroughs that have accelerated protein structure determination. Among these advances are high-brightness photon sources such as X-ray free-electron lasers (XFELs), fast read-out detectors (e.g. CSPAD, AGIPD and EIGER) and novel sample-delivery methods (e.g. electrospun liquid microjets, microfluidic devices, GDVN injector and high-viscosity injector) (Ayvazyan et al., 2006; Feld et al., 2015; Huang et al., 2015; Sierra et al., 2012; Weierstall et al., 2014, 2012). Serial femtosecond crystallography (SFX) at XFELs, in which diffraction snapshots are collected from thousands of nano- or microcrystals in random orientations (Chapman et al., 2011), has solved two major technical challenges of conventional synchrotron singlecrystal methods: (1) the need for production of large, well diffracting crystals and (2) inevitable radiation damage associated with X-ray exposures. In addition, SFX enabled timeresolved studies of conformational transitions in proteins with a sub-picosecond resolution allowing insights to be gained into molecular mechanisms of their function (Kupitz et al., 2014; 
Mizohata et al., 2018; Olmos et al., 2018; Pande et al., 2016; Tenboer et al., 2014). However, owing to the scarcity of XFEL facilities, with only five operational worldwide [the Linac Coherent Light Source (LCLS) at the SLAC National Accelerator Laboratory, in Menlo Park, California, USA; the SACLA in Harima, Japan; the European-XFEL in Hamburg, Germany; the Pohang Accelerator Laboratory-XFEL (PALXFEL) in Pohang, South Korea; and the Swiss-Free Electron Laser (SwissFEL) at the Paul Scherrer Institute in Villigen, Switzerland] and lack of beam time availability, serial millisecond crystallography (SMX) experiments at microfocus monochromatic beamlines at storage-ring-based synchrotron radiation sources has become a reliable alternative in certain cases. Microfocus beamlines optimized for macromolecular crystallography at third-generation synchrotrons can produce highly brilliant (up to $10^{13}$ photons $\mathrm{s}^{-1}$ ) and highly focused (as small as $1 \mu \mathrm{m}) \mathrm{X}$-ray beams. They are also equipped with fastreadout detectors (e.g. PILATUS and EIGER), which have enabled a rapid expansion of the SMX approach to many synchrotron facilities, demonstrating its advantages compared with traditional single-crystal crystallography. It has also been shown that room-temperature SMX experiments at synchrotrons can outrun secondary radiation damage (Owen et al., 2012; Warkentin et al., 2013, 2017).

Since the first proof-of-concept SMX study (Gati et al., 2014), there has been considerable interest in improving this method to increase the spatial and temporal resolution for studying protein structures and dynamics. Typically, synchrotron sources such as undulators and wigglers produce a polychromatic X-ray beam with a broad bandwidth $(\Delta E / E \simeq$ $10^{-1}-10^{-2}$ ). An X-ray monochromator can select a particular energy and narrow the bandwidth $\left(\Delta E / E \simeq 10^{-4}\right)$. With monochromatic X-ray beams, only a small fraction of lattice planes diffracts at any given orientation of the crystal. Therefore, the crystal has to be rotated to bring other planes into the diffracting position in order to collect full reflections. A 'drawback' of the monochromatic SMX technique is that thousands of diffraction patterns need to be collected from microcrystals for a complete data set because each pattern is essentially a 'still' and therefore all observed reflections are only partially recorded. With pink X-ray beams (bandwidth on the order of $\Delta E / E \simeq 5 \times 10^{-2}$ ), a large number of lattice planes diffract simultaneously as the Bragg condition is satisfied for each of the planes by at least one wavelength of the spectrum so that intensities of most reflections are fully recorded (Moffat, 1998; Ren et al., 1999). Thus, a much smaller number of diffraction patterns are needed with a pink beam to build a complete data set compared with a monochromatic beam and, therefore, the time and sample volume needed for structure determination are drastically reduced.

Historically, time-resolved macromolecular crystallography at ambient temperature has been conducted using Laue diffraction techniques. The Laue method has been applied to the study of photoreceptor intermediates, ligand photolysis, and allosteric action in heme proteins, enzymatic reactions, ligand-enzyme interactions, viruses and viral drug complexes (Bourgeois \& Royant, 2005; Hajdu \& Johnson, 1990; Neutze \&
Moffat, 2012; Šrajer \& Schmidt, 2017; Stoddard, 2001). Moffat and colleagues have pioneered this field, conducting experiments at CHESS, NSLS, ESRF and the Advanced Photon Source (APS) beamlines (Bourgeois et al., 1996; Genick et al., 1997; Ihee et al., 2005; Knapp et al., 2006; Moffat et al., 1984; Ren et al., 2012; Schmidt et al., 2010, 2005). A number of other groups also played a major role in the development of the field and conducted experiments at CHESS (Fülöp et al., 1994), Daresbury (Hajdu et al., 1987), NSLS (Bolduc et al., 1995; Stoddard et al., 1998), DESY (Schlichting et al., 1990), the ESRF (Bourgeois et al., 2003; Schotte et al., 2003, 2004; Wöhri et al., 2010) and the Photon Factory Advanced Ring (Nozawa et al., 2007). BioCARS at APS specializes in time-resolved pump-probe experiments where short laser pulses are used as the pump and high flux, polychromatic X-ray pulses are used as the probe. The pink beam at the BioCARS beamline, (sector 14) 14-ID-B, with $5.1 \times 10^{16}$ photons s ${ }^{-1}$, offers an average photon flux 100 times higher than the monochromatic beams and is coupled with the $100 \mathrm{ps}$ time-resolution capability, which provides a dependable platform for probing structural intermediates of essential biological macromolecules.

The first proof-of-concept serial crystallography (SX) experiment using a pink X-ray beam at BioCARS was recently reported by Meents et al. (2017). They determined the structures of proteinase $\mathrm{K}$ and phycocyanin using $10-20 \mu \mathrm{m}$ and $30-40 \mu \mathrm{m}$ sized crystals, respectively, by fixed-target SX using a pink X-ray beam. Here, we report the first proof-of-concept high-viscosity injector-based pink-beam SX experiments using lipidic cubic phase (LCP) as a crystal-carrier medium. Two target proteins were chosen for this pilot experiment: (1) the human $\mathrm{A}_{2 \mathrm{~A}}$ adenosine receptor $\left(\mathrm{A}_{2 \mathrm{~A}} \mathrm{AR}\right)$ (Liu et al., 2012), one of the best-studied $\mathrm{G}$ protein-coupled receptors (GPCRs); and (2) proteinase $\mathrm{K}(\mathrm{PK})$, a commercially available serine protease used in numerous studies to identify disordered regions. The structures of $\mathrm{A}_{2 \mathrm{~A}} \mathrm{AR}$ and $\mathrm{PK}$ were determined to resolutions of 4.2 and $1.8 \AA$, respectively. Laue data-processing software, Precognition (Renz Research Inc.), used at BioCARS was able to index the strong images obtained for PK data. However, it could not index $\mathrm{A}_{2 \mathrm{~A}} \mathrm{AR}$ data that consisted of weak and sparse Laue diffraction patterns. An alternative hit-finding and indexing strategy was necessary to analyze $A_{2 A} A R$ data, which was shown to be essential when dealing with weak and sparse Laue diffraction patterns from microcrystals.

\section{Results}

To demonstrate the proof-of-concept of the LCP injectorbased pink-beam SX at the BioCARS beamline (14-ID-B), we tested two target proteins: $\mathrm{A}_{2 \mathrm{~A}} \mathrm{AR}$ (an integral membrane protein) and PK (a soluble protein). In our study, we used an LCP injector designed by Uwe Weierstall at Arizona State University (Weierstall et al., 2014) to deliver microcrystals of a size range between $5 \mu \mathrm{m}\left(\mathrm{A}_{2 \mathrm{~A}} \mathrm{AR}\right)$ and $10-15 \mu \mathrm{m}(\mathrm{PK})$. Microcrystals of PK were first obtained by the batch crystallization method, then pelleted, re-suspended in the crystal- 
(a)
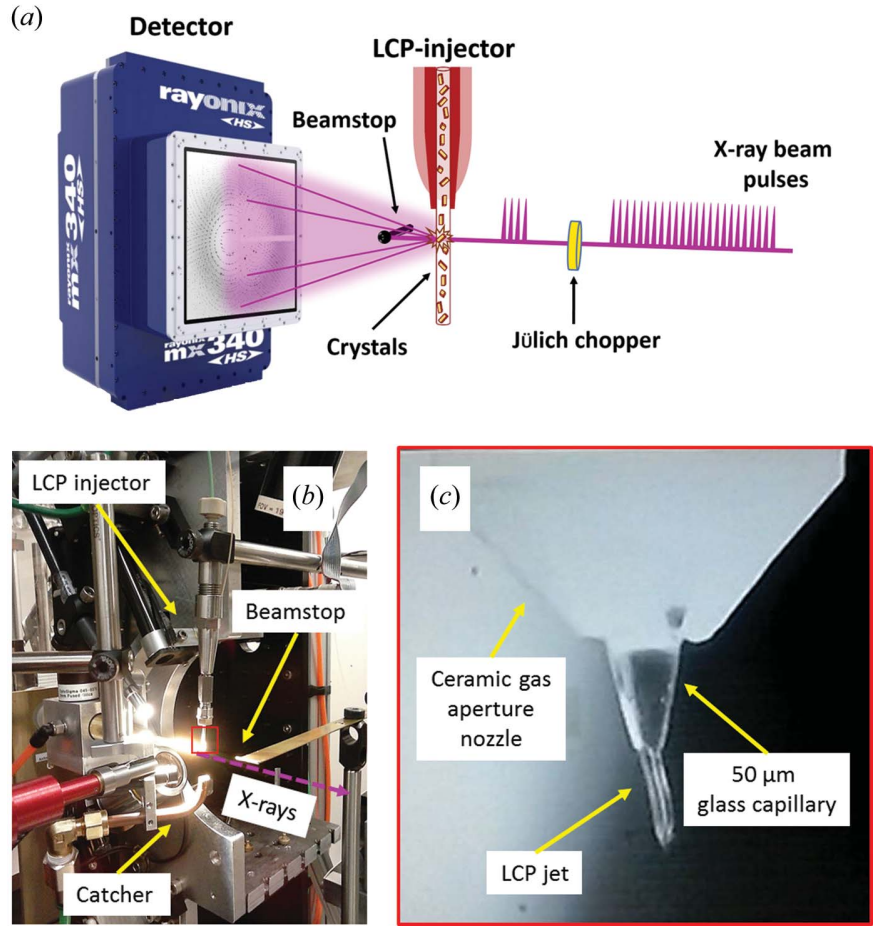

Figure 1

Experimental setup at the BioCARS beamline, 14-ID-B. (a) Schematic diagram of the setup. APS was operating in the 24-pulse mode. A Jülich chopper was used to choose the desired number of pulses. A Rayonix detector MX340HS was used to record crystal diffraction. (b) LCP injector (Weierstall et al., 2014) mounted on translation stages. The catcher and beamstop are also shown. (c) Closer view of the red boxed area in $(b)$ showing the LCP stream extruding out of a glass capillary with a $50 \mu \mathrm{m}$ internal diameter, which was inserted into a ceramic injectionmolded gas aperture nozzle.

lization buffer to the desired concentration and finally reconstituted into LCP as previously described (MartinGarcia et al., 2017). The resulting PK crystal-laden LCP mesophase was then transferred into an LCP injector. Microcrystals of $\mathrm{A}_{2 \mathrm{~A}} \mathrm{AR}$ were grown in LCP and transferred to an LCP injector directly in the same medium as used for crystallization. Data collection was carried out with APS operating in a 24-bunch mode, in which 24 pulses of 100 ps duration (FWHM) are equally separated by $153 \mathrm{~ns}$. The experimental setup is shown in Fig. 1. Diffraction data were initially collected using a $25 \times 15 \mu \mathrm{m}$ beam by choosing a single-pulse exposure of 100 ps duration to deliver $7.5 \times 10^{9}$ photons per pulse to a single crystal. However, only relatively low-resolution diffraction patterns were observed, indicating that more photons were needed to obtain a sufficient signal at higher resolution. Subsequently, photon flux was increased by using 4 and 24 consecutive pulses for $\mathrm{PK}$ and $\mathrm{A}_{2 \mathrm{~A}} \mathrm{AR}$, respectively. Complete data sets were recorded and structures of the proteins were determined as we describe below.

\subsection{Crystal structure of $P K$ in LCP medium with four consecutive $\mathrm{X}$-ray pulses}

PK microcrystals $(10-15 \mu \mathrm{m})$ embedded into LCP medium were delivered into the pink X-ray beam using a constant flow
Table 1

Data-collection and refinements statistics.

Values in parentheses are for the highest resolution shell.

\begin{tabular}{|c|c|c|}
\hline & $\mathrm{A}_{2 \mathrm{~A}} \mathrm{AR} \dagger$ & $\mathrm{PK} \ddagger$ \\
\hline Crystal size $(\mu \mathrm{m})$ & $5 \times 5 \times 2$ & $15 \times 10 \times 5$ \\
\hline Crystal-to-detector distance $(\mathrm{mm})$ & 250 & 250 \\
\hline Duration $(\mathrm{h})$ & 7 & $\sim 1$ \\
\hline Sample flow rate $\left(\mathrm{nl} \min ^{-1}\right)$ & 60 & 29.4 \\
\hline Exposure time $(\mu \mathrm{s})$ & 3.53 & 0.46 \\
\hline No. of bunches & 24 & 4 \\
\hline Radiation dose per crystal (kGy) & 210 & 30 \\
\hline Protein/carrier volume $(\mu \mathrm{l})$ & 25.2 & 2.0 \\
\hline Maximum resolution observed (Å) & 3.5 & 1.8 \\
\hline Resolution $(\AA)$ & $50.0-4.2(4.3-4.2)$ & $57.8-1.8(1.85-1.8)$ \\
\hline Space group & $C 222_{1}$ & $P 4_{3} 2_{1} 2_{2}$ \\
\hline$a, b, c(\AA)$ & $40.0,179.0,142.0$ & $68.3,68.3,108.3$ \\
\hline$\alpha, \beta, \gamma\left(^{\circ}\right)$ & $90,90,90$ & $90,90,90$ \\
\hline No. of collected images & 250000 & 30000 \\
\hline No. of hits/indexed patterns & 7363/771 & $946 / 626(132) \S$ \\
\hline$\langle I / \sigma(I)\rangle(\mathrm{SNR})$ & $4.5(4.2)$ & $23.3(13.3)$ \\
\hline Multiplicity & $11.5(8.1)$ & 9 ब \\
\hline Completeness (\%) & $87.8(78.9)$ & $61.3(13.7) \dagger \dagger$ \\
\hline CC* $(\%)$ & $94.3(80.0)$ & N/A株 \\
\hline$R_{\text {split }}(\%)$ & $27.0(26.2)$ & 10.2 - \\
\hline Total No. of reflections & 4021 & 14910 \\
\hline No. of reflections in refinement & 3179 & 13447 \\
\hline $\begin{array}{l}\text { No. of free reflections } \\
\text { in refinement }\end{array}$ & 404 & 1463 \\
\hline$R_{\text {work }} / R_{\text {free }}(\%)$ & $25.0 / 28.8$ & $12.9 / 17.5$ \\
\hline No. of atoms & 3003 & 2176 \\
\hline Protein & 2979 & 2033 \\
\hline $\begin{array}{l}\text { Water and others } \\
\text { (ligands or ions) }\end{array}$ & 24 & 143 \\
\hline Average $B$ value $\left(\AA^{2}\right)$ & 59.3 & 9.8 \\
\hline \multicolumn{3}{|l|}{ R.m.s deviations from ideal values } \\
\hline Bonds $(\AA)$ & 0.006 & 0.02 \\
\hline Angles $\left({ }^{\circ}\right)$ & 1.0 & 1.8 \\
\hline \multicolumn{3}{|l|}{ Ramachandran plot statistics (\%) } \\
\hline Favored & 97.4 & 97.5 \\
\hline Allowed & 2.6 & 2.5 \\
\hline Disallowed & 0 & 0 \\
\hline Rotamer outliers & 0 & 0 \\
\hline PDB entry & $6 \mathrm{mh} 8$ & $6 \mathrm{mh} 6$ \\
\hline
\end{tabular}

$\dagger$ The structure of $\mathrm{A}_{2 \mathrm{~A}} \mathrm{AR}$ determined from Laue data processed using CrystFEL. $\ddagger$ The structure of PK determined from Laue data processed using program Precognition (Renz Research Inc.) § Statistics below are from merging the best 132 indexed images. Images were selected based on the highest number of detected reflections from the total of 626 indexed images. Only overall multiplicity and $R_{\text {merge }}$ were reported by Precognition. Listed is $R_{\text {merge }}\left(F^{2}\right)$. †† Completeness listed is for data merged at $3 \sigma$ level, standard experience-based cut-off for merging Laue data processed with Precognition as a compromise between $R_{\text {merge }}$ and last shell completeness. In addition, Precognition uses a resolution-dependent wavelength bandwidth (Ren et al., 1999) to prevent overprediction of data at high resolution. ft Not reported by Precognition (Renz Research Inc.).

rate of $29.4 \mathrm{nl} \mathrm{min}-1$ with a total data-collection time of $1 \mathrm{~h}$, which resulted in a sample consumption of $2.0 \mu \mathrm{l}$. High-quality diffraction data were collected using four consecutive $100 \mathrm{ps}$ pink X-ray beam pulses separated by $153 \mathrm{~ns}$ so that each crystal was exposed for a total of $460 \mathrm{~ns}$ (actual X-ray exposure time of $400 \mathrm{ps}$ ), resulting in a dose per crystal of $30 \mathrm{kGy}$. A total of 30000 images were recorded, of which 946 were identified as crystal hits (hit rate $3.1 \%$ ) and 626 indexed, resulting in a combined indexing and hit rate of $2.1 \%$. The structure of PK was determined to a resolution of $1.8 \AA$ in space group $P 4_{3} 2_{1} 2$ using only the best 132 patterns out of a total of 626 patterns that were indexed (see Materials and methods). The final data-collection and refinement statistics 
are shown in Table 1. A Laue diffraction pattern with diffraction up to a resolution of $1.8 \AA$ from a single microcrystal of PK in LCP is shown in Fig. S1A in the Supporting information. The Bragg reflections are well separated and show a subtle elongation in the radial direction indicating a low degree of crystal mosaicity. Phasing was performed by molecular replacement using the room-temperature SMX structure we recently reported from monochromatic data collected at GM/CA (23-ID-D) at APS as a search model [Protein Data Bank (PDB) entry 5uvl; Martin-Garcia et al., 2017]. The structure of PK with pink-beam SX presented herein was refined to a resolution of $1.8 \AA$. The final refinement resulted in $R_{\text {work }}$ and $R_{\text {free }}$ values of $12.9 \%$ and $17.5 \%$, respectively.

We compared our structure with those obtained by conventional monochromatic diffraction experiments from a single crystal at room temperature (PDB entry 2prk; Betzel et al., 1988) and from cryo-cooled crystals (PDB entry 5avj; Yazawa et al., 2016) as well as with the structure recently reported by Meents and co-workers using pink-beam SX on chips (PDB entry 5mjl; Meents et al., 2017). All r.m.s.d. values are shown in Table S1. Overall, our structure superimposed very well with all PK structures for all $\mathrm{C}^{\alpha}$ atoms (r.m.s.d. < $0.18 \AA$ ). Superimposition of all atoms $(0.35 \AA<$ r.m.s.d. $<$
$0.73 \AA$ ) indicates that small differences were, however, observed in the solvent-exposed regions. The average $B$ factor is $9.8 \AA^{2}$. The electron-density maps of our pink-beam SX structure show a high level of structural detail. The 136 water molecules identified in our model and the $2 m F_{\mathrm{o}}-D F_{\mathrm{c}}$ electron-density maps around the two $\mathrm{Ca}^{2+}$ ions can be used to assess the high quality of our PK structure (Fig. 2). Furthermore, a comparison of the $m F_{\mathrm{o}}-D F_{\mathrm{c}}$ electron-density maps of our structure with those from monochromatic data obtained using SMX (Martin-Garcia et al., 2017) is shown in Fig. 2. To ensure that model structural bias is absent in our PK structure, the residue fragment between Ala226 and Tyr236 was deleted from the model, and simulated-annealing OMIT maps were calculated (Terwilliger et al., 2008). The strong positive peaks visible in place of all omitted residues indicate the absence of model bias in our model (Fig. 3).

\subsection{Crystal structure of $A_{2 A} A R$ in LCP medium with 24 consecutive $\mathrm{X}$-ray pulses}

Because of the small size of the $\mathrm{A}_{2 \mathrm{~A}} \mathrm{AR}$ crystals $(5 \mu \mathrm{m})$ and the relatively large X-ray beam $[25 \times 15 \mu \mathrm{m}(H \times V)]$, only weak diffraction to low resolution was observed using 4 consecutive X-ray pulses indicating that a much higher (a)

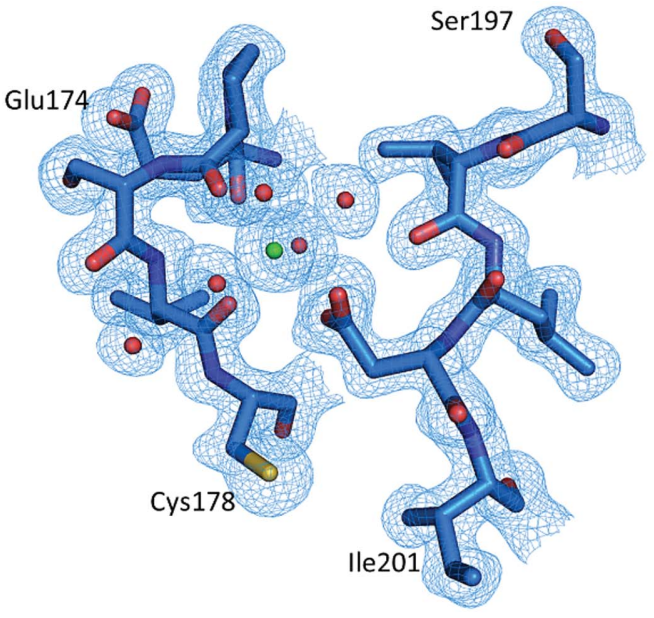

(b)

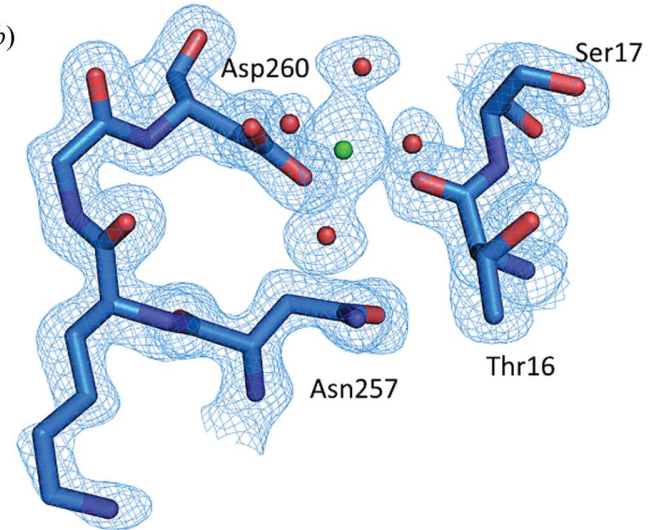

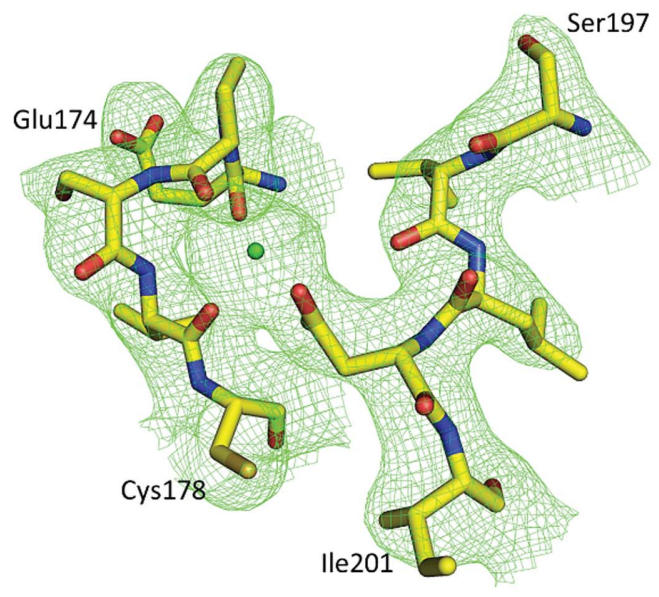

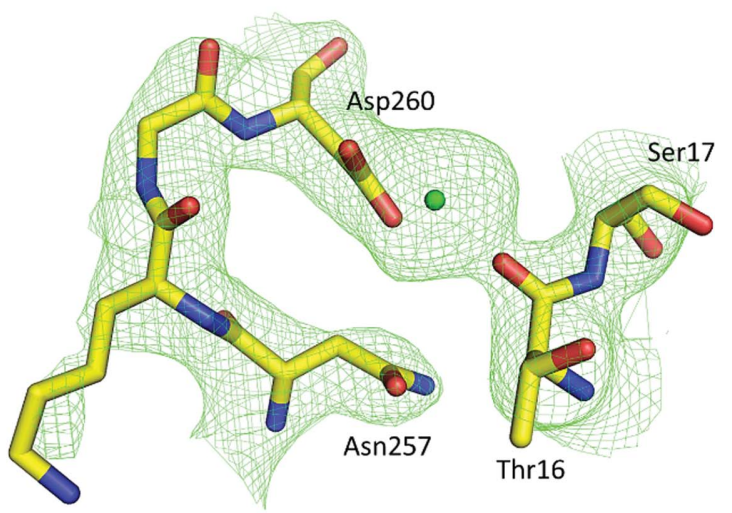

Figure 2

Comparison of the quality of the electron-density maps $\left(2 m F_{\mathrm{o}}-D F_{\mathrm{c}}\right)$ of the PK structures determined using a pink beam (left panels) and a monochromatic beam (Martin-Garcia et al., 2017) (right panels) contoured at 1.5 $\sigma$. (a) Electron-density map around the Ca ${ }^{2+}$ site 1 . (b) Electron-density map around the $\mathrm{Ca}^{2+}$ site $2 . \mathrm{Ca}^{2+}$ ions and water molecules are represented as green and red spheres. Residues around $\mathrm{Ca}^{2+}$ ions are shown in a stick representation. 
(a)

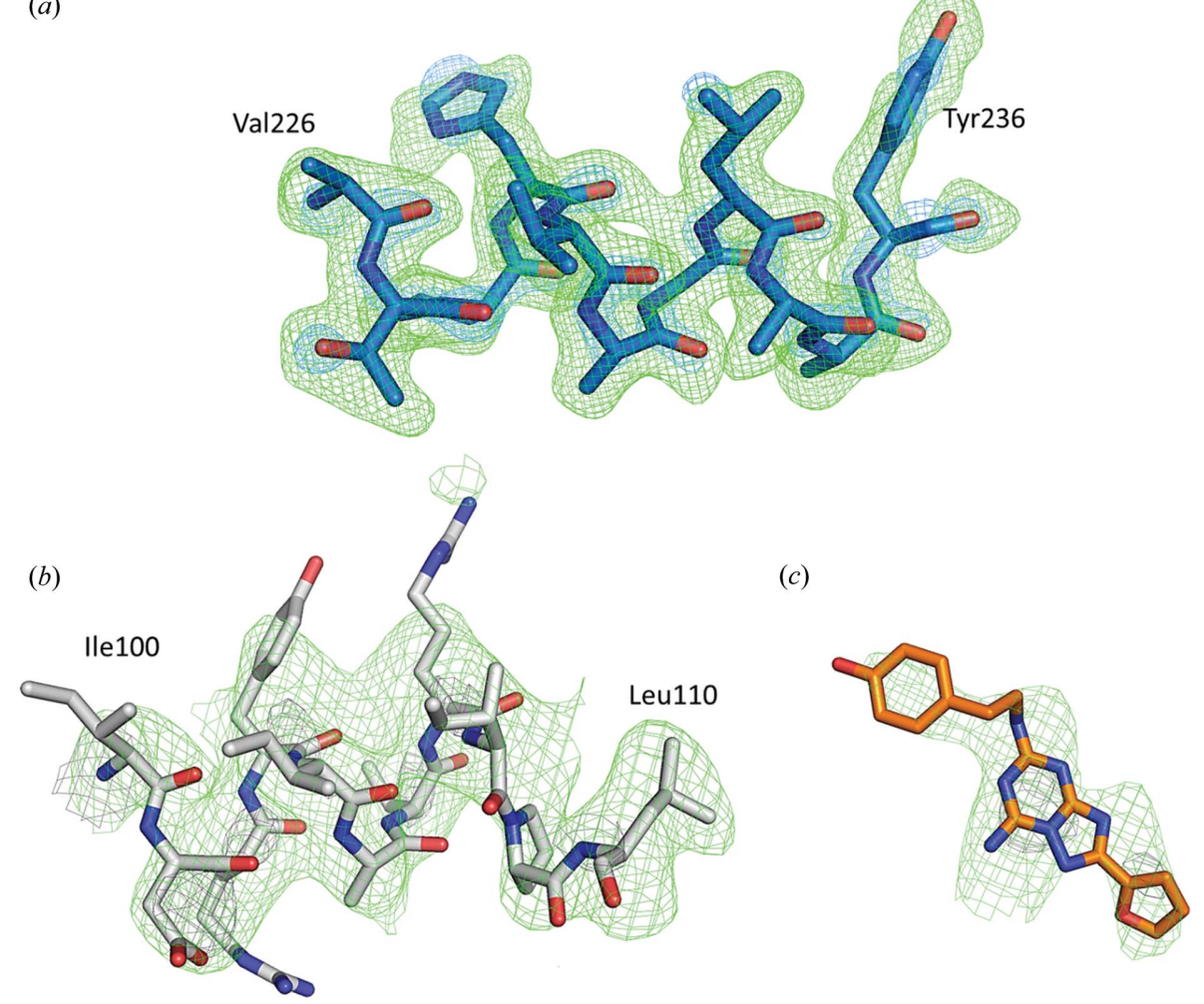

Figure 3

Difference electron-density maps of $\mathrm{PK}(a)$ and $\mathrm{A}_{2 \mathrm{~A}} \mathrm{AR}[(b)$ and $(c)]$ structures to illustrate the absence of model bias. Residue fragment Val226-Tyr236 of PK structure (a), Ile100-Leu110 of $\mathrm{A}_{2 \mathrm{~A}} \mathrm{AR}(b)$ and ligand ZM241385 (c) were deleted from models and simulated-annealing OMIT maps $2 m F_{\mathrm{o}}-D F_{\mathrm{c}}$ (gray) and $m F_{\mathrm{o}}-D F_{\mathrm{c}}$ (green) were calculated. In all cases [ $(a)$ and $\left.(b)\right]$, OMIT maps $2 m F_{\mathrm{o}}-D F_{\mathrm{c}}$ are contoured at $1.5 \sigma$ and $m F_{\mathrm{o}}-D F_{\mathrm{c}}$ are contoured at $2.5 \sigma$. Omitted residues are shown for clarity. The positive electron density, where original residues were, is in good agreement with the final structural model of $\mathrm{PK}$ and $\mathrm{A}_{2 \mathrm{~A}} \mathrm{AR}$.

number of photons were needed to collect a data set from such small crystals. We, therefore, used 24 consecutive pulses so that each $\mathrm{A}_{2 \mathrm{~A}} \mathrm{AR}$ crystal was exposed for a total of $3.53 \mu \mathrm{s}$ (actual X-ray exposure of $2.4 \mathrm{~ns}$ ) and received a total of $1.82 \times$ $10^{11}$ photons and a radiation dose per crystal of $210 \mathrm{kGy}$. Microcrystals of $\mathrm{A}_{2} \mathrm{~A} A \mathrm{R}$ were injected into the X-ray pinkbeam path at a constant flow rate of $60 \mathrm{nl} \mathrm{min}{ }^{-1}$ and were measured for $7 \mathrm{~h}$ with an overall LCP sample consumption of $25.2 \mu \mathrm{l}$. A total of 250000 images were recorded, of which 7363 were identified as hits ( $3 \%$ hit rate) and 771 were successfully indexed (10.5\% indexing rate), integrated, scaled and merged in space group $C 222_{1}$ by CrystFEL (version 0.6.3; White et al., 2012, 2013, 2016), resulting in a combined hit and indexing rate of $0.3 \%$ (see Material and methods and Table 1 for details).

Fig. S1B shows a Laue diffraction pattern from a single $\mathrm{A}_{2 \mathrm{~A}} \mathrm{AR}$ microcrystal. The $\mathrm{A}_{2 \mathrm{~A}} \mathrm{AR}$ structure was solved by molecular replacement using our recently reported SMX structure (PDB entry 5uvi; Martin-Garcia et al., 2017) without the ligand ZM241385 and lipids. The final structure was refined to a resolution of $4.2 \AA$ with an $R_{\text {work }}$ and $R_{\text {free }}$ of $25.0 \%$ and $28.8 \%$, respectively. Final data-collection and refinement statistics are shown in Table 1. Our pink-beam electron-density maps show a relatively high level of structural detail (Fig. 4). In fact, despite the low resolution of the structure $(4.2 \AA)$, the good quality of the electron-density maps allowed us to model the ligand ZM241385 [Fig. 4(b)]. The absence of significant model bias in our $\mathrm{A}_{2 \mathrm{~A}} \mathrm{AR}$ pink-beam structure was demonstrated by deleting the fragment between His100 and Leu110 from the model and the ligand ZM241385, and calculating simulated-annealing OMIT maps. The strong positive peaks visible in place of omitted residues indicate the absence of model bias in our model (Fig. 3). A comparison of the $2 m F_{\mathrm{o}}-$ $D F_{\mathrm{c}}$ electron-density maps of $\mathrm{A}_{2 \mathrm{~A}} \mathrm{AR}$ obtained by pink-beam serial crystallography with those obtained from SMX using monochromatic data (Martin-Garcia et al., 2017) is also shown in Figs. 4(c) and $4(d)$.

To ensure the validity of our procedure, a comparison of our Laue $\mathrm{A}_{2 \mathrm{~A}} \mathrm{AR}$ crystal structure with highresolution structures obtained by monochromatic diffraction experiments using either SFX (Batyuk et al., 2016), cryo-cooled single crystals (Liu et al., 2012) or SMX (Martin-Garcia et al., 2017) reveals only small differences between the structures. All structures are very similar to each other, with r.m.s.d. values $<0.5 \AA$ for all $\mathrm{C}^{\alpha}$ atoms (Table S1). Larger differences were found around the side chains of highly solvent-exposed residues as expected. In addition, structural discrepancies were slightly higher along the backbone in the BRIL fusion protein (Table S1).

\subsection{Radiation damage}

To evaluate potential site-specific radiation-damage effects on the $\mathrm{A}_{2 \mathrm{~A}} \mathrm{AR}$ structure, we calculated the $2 m F_{\mathrm{o}}-D F_{\mathrm{c}}$ and $m F_{\mathrm{o}}-D F_{\mathrm{c}}$ electron-density maps and looked at those regions of the proteins that are more susceptible to radiation damage such as disulfide bonds, which were carefully checked for residual electron densities. $\mathrm{A}_{2 \mathrm{~A}} \mathrm{AR}$ has four disulfide bonds (Cys71-Cys159, Cys74-Cys146, Cys77-Cys166, and Cys259Cys262) in its structure. No significant residual electron densities were found around these disulfide bonds. To further characterize the potential effects of site-specific radiation damage, we calculated the structure-factor amplitude Fourier difference $\left(F_{\mathrm{o}}-F_{\mathrm{o}}\right)$ maps comparing the data sets obtained in this study by serial pink X-ray beam crystallography with the high-resolution structure collected at an XFEL (PDB entry 5k2c; Batyuk et al., 2016). As shown in Fig. S2, no significant electron-density peaks around any of the disulfide bonds were found at a contour level of $3 \sigma$, which indicates that the site- 
(a)

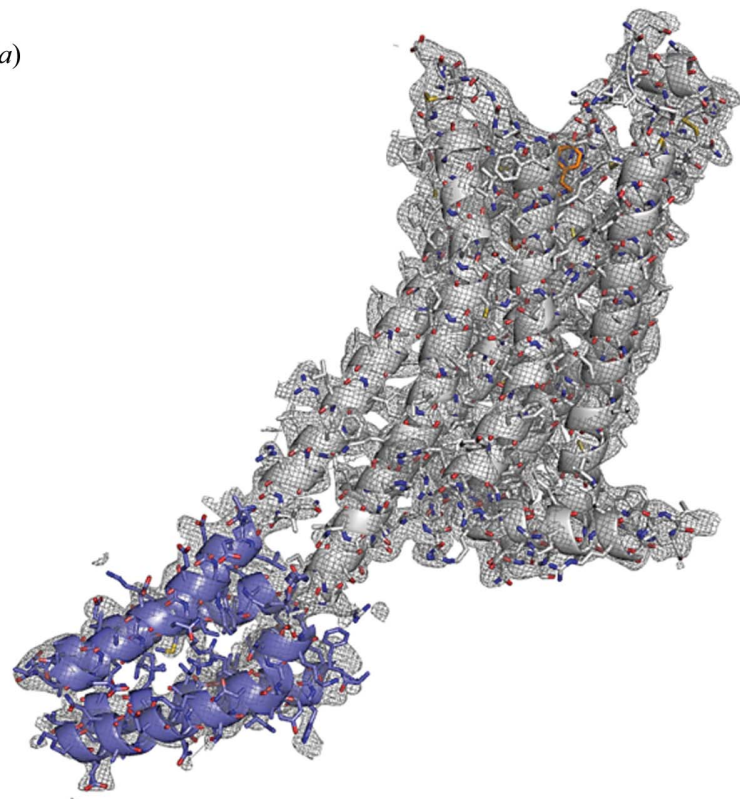

(c)

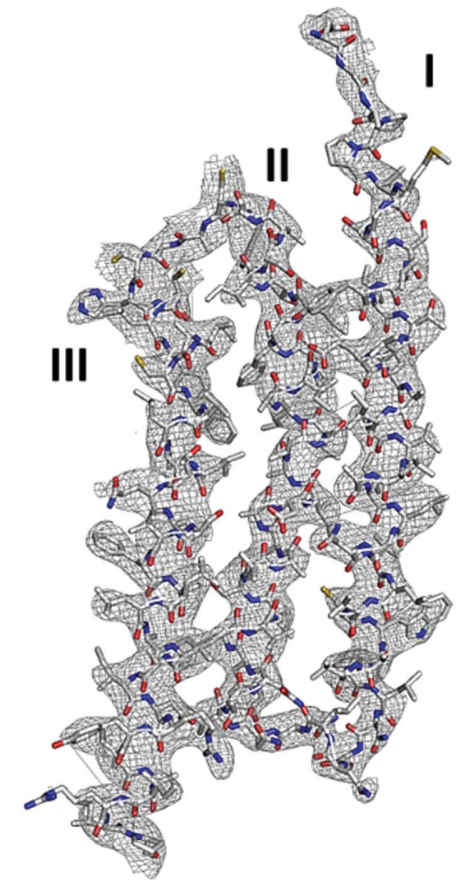

(b)

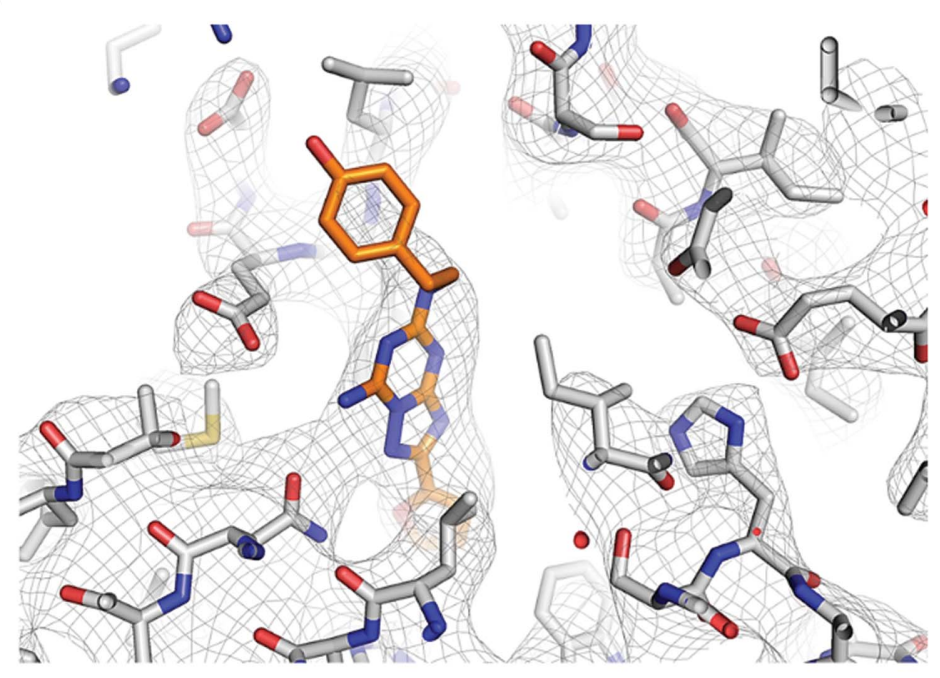

(d)

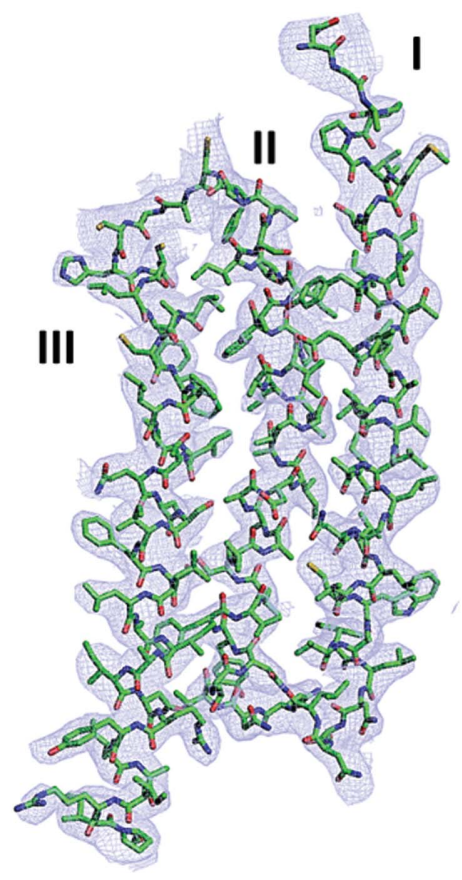

Figure 4

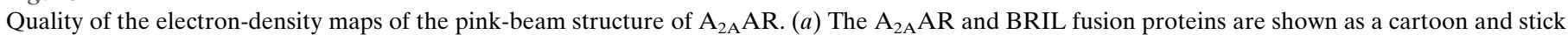
representation in white and violet, respectively. (b) Difference electron-density maps $\left(2 m F_{\mathrm{o}}-D F_{\mathrm{c}}\right.$ at $\left.1.5 \sigma\right)$ around the ligand ZM241385 (orange stick representation) and neighboring residues. $(c)$ and $(d)$ Comparison of the quality of the $2 m F_{\mathrm{o}}-D F_{\mathrm{c}}$ electron-density maps (at $\left.1.5 \sigma\right)$ around the residues, shown as sticks for helices I, II and III of the pink-beam $\mathrm{A}_{2 \mathrm{~A}} \mathrm{AR}$ structure $(c)$ and the monochromatic $\mathrm{A}_{2 \mathrm{~A}} \mathrm{AR}$ structure (d) (Martin-Garcia et al., 2017).

specific radiation damage is negligible or not visible at this resolution and that the disulfide bonds are not completely broken. A similar analysis was carried out with our PK structure. The $F_{\mathrm{o}}-F_{\mathrm{o}}$ maps comparing our PK pink-beam structure with the structure from a single cryo-cooled crystal (PDB entry: 5avj; Yazawa et al., 2016) were calculated and no signs of site-specific radiation damage in the electron density around the two disulfide bridges (Cys34-Cys123 and Cys178Cys249) were observed (Fig. S3), as expected from the low dose used (30 kGy).
2.4. Comparison of $A_{2 A} A R$ and $P K$ structures from mono- and polychromatic diffraction methods

We compared the structures of $\mathrm{A}_{2 \mathrm{~A}} \mathrm{AR}$ and $\mathrm{PK}$ determined here using pink-beam SX with those we recently obtained using a monochromatic beam at GM/CA (Martin-Garcia et al., 2017). All data-collection statistics are shown in Table S2. To determine the structure of $\mathrm{A}_{2 \mathrm{~A}} \mathrm{AR}$ to $3.2 \AA$ using a monochromatic beam required a total of 5287 indexed patterns and nearly $14 \mathrm{~h}$ of continuous data collection (503 006 snapshots) in which $52.3 \mu \mathrm{l}$ of sample was consumed at an average flow 
Table 2

Data-collection statistics of PK data to $1.8 \AA$ at different $I / \sigma$ cut-offs used for data merging.

The structure of PK was determined from Laue data processed using program Precognition (Renz Research Inc.). Values in parentheses are for the highest resolution shell.

\begin{tabular}{|c|c|c|c|c|c|}
\hline & $1.0 \sigma$ & $1.5 \sigma$ & $2.0 \sigma$ & $3.0 \sigma$ & $3.0 \sigma$ \\
\hline No. of collected images & 30000 & 30000 & 30000 & 30000 & 30000 \\
\hline No. of hits/indexed patterns & $946 / 626(132) \dagger$ & $946 / 626(132) \dagger$ & $946 / 626(132) \dagger$ & $946 / 626(132) \dagger$ & $946 / 626 \ddagger$ \\
\hline $\mathrm{I} / \sigma(\mathrm{SNR})$ & $13.2(7.3)$ & $16.4(8.7)$ & $19.1(10.2)$ & $23.3(13.3)$ & $30.4(12.6)$ \\
\hline Completeness (\%) & $95.3(71.9)$ & $88.5(52.1)$ & $77.7(34.8)$ & $61.3(13.7)$ & $63.4(15.6)$ \\
\hline$R_{\text {merge }}\left(F^{2}\right)(\%) \S$ & 19.3 & 15.4 & 13 & 10.2 & 12.5 \\
\hline No. of reflections & 23224 & 21477 & 18860 & 14910 & 15446 \\
\hline No. of reflections in refinement & 20945 & 19366 & 16989 & 13447 & 13447 \\
\hline
\end{tabular}

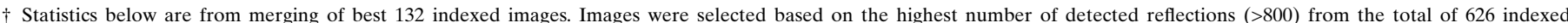

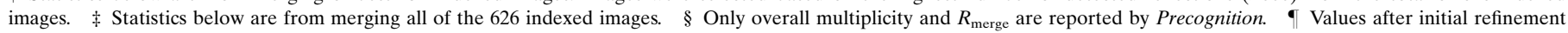
without solvent molecules. †† Values of final model after adding all solvent molecules. 柿 Structure was determined using 132 indexed paterns.

rate of $56 \mathrm{nl} \mathrm{min}{ }^{-1}$ (Martin-Garcia et al., 2017). The weak Laue diffraction data were difficult to index resulting in a lower indexing rate compared with the monochromatic experiments at GM/CA and thus 250000 snapshots were recorded at BioCARS to facilitate structure determination (Table S2). In contrast to the experiment at GM/CA, only $7 \mathrm{~h}$ and half of the sample volume $(25.2 \mu \mathrm{l})$ at a similar average flow rate $\left(60 \mathrm{nl} \mathrm{min}{ }^{-1}\right)$ were needed to collect a full data set. A comparison of the quality of the electron-density maps for $\mathrm{A}_{2 \mathrm{~A}} \mathrm{AR}$ with a pink beam and a monochromatic beam is shown in Fig. 4. In the case of PK, eight times fewer indexed patterns [only 132 strong patterns with at least 50 peaks above a signal-to-noise ratio (SNR) of $3 \sigma$ ] were required to determine the high-resolution structure by pink-beam SX compared with using the monochromatic beam at GM/CA (817 indexed patterns) from a sample of microcrystals of similar size and concentration (Table S2).

As pointed out by Meents and co-workers (Meents et al., 2017; Ren et al., 1999), the completeness of Laue data sets is typically lower than that of a monochromatic beam. Meents et al. attributed this lower completeness to the more challenging data processing, such as resolving spatial overlap of diffraction spots. Difficulty in achieving very high completeness also results from Laue geometry (Ren et al., 1999). A more conservative SNR cut-off criterion of $3 \sigma$ is also typically applied to merged Laue data to exclude poorly measured reflections resulting from wavelengths of very low intensity in the incident X-ray spectrum. This also results in lower completeness particularly at higher resolution (Meents et al., 2017). To assess if the $3 \sigma$ cut-off applied to our PK pink-beam data was adequate, we also merged data at lower cut-offs of $1.0 \sigma, 1.5 \sigma$, and $2.0 \sigma$. These trial data sets were processed the same way as the $3 \sigma$ cut-off data set. Data-collection and refinement statistics for these three data sets are shown in Table 2 . The $2 \sigma$ or $3 \sigma$ cut-off as typical cut-offs for Laue data mainly comes from empirical experience in dealing with small signals in time-resolved difference maps. At low sigma cut-offs (resulting in higher $R_{\text {merge }}$ values), difference maps are typically noisier and difference signal is weaker (as compared with noise). Difference maps therefore become more difficult to interpret and, sometimes, weak signal cannot even be observed. In addition to higher sigma cut-offs in time-resolved experiments, weighting down of poorly measured structure factors is also typically applied, which in a way is reducing completeness further. For an illustration of how weighting affects the time-resolved difference-map signal see Šrajer $e t$ al. (2001). Thus, $3 \sigma$ cut-off was used in our data processing and resulted in improved data quality as judged by the higher refinement $R_{\text {work }}$ values as well as the higher $R_{\text {work }} / R_{\text {free }}$ gaps $(\sim 7 \%)$.

\section{Discussion}

In this study, we demonstrated the feasibility of the roomtemperature LCP injector-based pink-beam SX at the BioCARS beamline at APS, which can be translated to any other synchrotron sources equipped with pink X-ray beams. We used an LCP injector (Weierstall et al., 2014) to deliver microcrystals into the $25 \times 15 \mu \mathrm{m}(H \times V)$ pink X-ray beam path. Diffraction data were collected when APS was operating in a 24-bunch mode. We performed experiments using 4 and 24 consecutive pulses. To validate the proof-of-principle of the pink-beam SX approach, we determined the structures of the human adenosine receptor $\mathrm{A}_{2 \mathrm{~A}} \mathrm{AR}$ and the reference protein PK. Despite the much lower resolution of the pink-beam $\mathrm{A}_{2 \mathrm{~A}} \mathrm{AR}$ structure in the present study compared with that obtained at XFELs (Batyuk et al., 2016), the resulting electron-density maps are of relatively good quality and comparable with those achieved using serial micro-crystallography with a monochromatic beam at a synchrotron source (MartinGarcia et al., 2017). In our analysis we find no evidence for site-specific radiation damage and the observed electron densities are not significantly biased despite the low resolution obtained for the $\mathrm{A}_{2 \mathrm{~A}} \mathrm{AR}$ structure.

The most widely used Laue data-processing software, Precognition (Renz Research Inc.), was able to index strong images from the PK data set but it could not index weak, streaky and sparse Laue diffraction patterns like those 
observed for $\mathrm{A}_{2 \mathrm{~A}} \mathrm{AR}$ crystals (Fig. S1). To this end, we adapted the standard pipeline developed for processing monochromatic serial crystallography data using CrystFEL with MOSFLM (White et al., 2012, 2013, 2016). Our justification in using this pipeline is that in streaky, sparse, pinkbeam patterns from small crystals, most measured Bragg peaks are sampled by the brightest part of the spectrum, i.e. the central-wavelength photons in the pink-beam distribution, which is critical for monochromatic auto-indexing algorithms. Another reason to use CrystFEL with MOSFLM for indexing and integration is to evaluate how well the current technology can be adapted to a difficult-to-process Laue data set and to determine where the software limitations lie so we can further develop a customized solution that can be of utility for future SX Laue diffraction experiments. We fully acknowledge that this is not a perfect process - CrystFEL with MOSFLM was developed for monochromatic beam serial diffraction experiments. Therefore, inherent limitations such as improper peak finding and peak over-prediction are present when grafting the approach to processing Laue diffraction data. These include the absence of typical Laue wavelength scaling prior to intensity merging (see Section 5.3 for a brief discussion). We also only used one wavelength as an input parameter despite pink-beam Laue diffraction experiments being conducted with photons of multiple wavelengths. However, even within such limitations we see acceptable statistics in our $\mathrm{A}_{2 \mathrm{~A}} \mathrm{AR}$ model as presented herein. Our results confirm the reasonable quality of the structure as well as the absence of visible radiation damage. Future developments in data processing of Laue diffraction from crystals measured in a serial fashion will aim to introduce a Laue prediction model, where predicted reflections per pattern are composites of predicted reflections for each wavelength in the Laue spectrum. Such a prediction algorithm automatically assigns a wavelength to each measured Bragg peak, which can then be applied to a wavelength scaled intensity merging algorithm. An illustration of the overall indexing quality of $\mathrm{A}_{2 \mathrm{~A}} \mathrm{AR}$ data is shown in Fig. S5 in which found spots and predicted reflections for each of the $\sim 770$ hits that went into the merge are shown.

In a recent study carried out at a synchrotron (GM/CA beamline at APS) using a monochromatic beam, we reported the high-quality structures of $\mathrm{A}_{2 \mathrm{~A}} \mathrm{AR}$ and PK (Martin-Garcia et al., 2017) from crystals delivered into the X-ray beam in a serial mode using an LCP injector (Weierstall et al., 2014). The number of indexed patterns needed for a complete data set was about several thousands, which is comparable with that required in SFX experiments using SASE X-ray beams at XFELs (Batyuk et al., 2016). In the pink-beam study reported here we have been able to determine the structures of $\mathrm{A}_{2 \mathrm{~A}} \mathrm{AR}$ and PK from microcrystals of similar sizes and concentration using a much smaller number of indexed patterns (a few hundreds). Two benefits of the increased bandwidth of pink beam over monochromatic beam are: (1) reflections falling within the limiting Ewald spheres are fully recorded and (2) more reflections fall within the Ewald sphere (Moffat et al. (1984). However, the SNR of a given reflection decreases if the increasing bandwidth leads to increased intensity because the background scattering is proportional to the incident intensity. The ideal bandwidth to fully record reflections with maximum SNR is probably slightly larger than that required to match the crystal mosaicity. The significant reduction in the number of indexed patterns required to determine the structure was possible because of the significantly wider bandwidth of the pink X-ray beam used at the BioCARS beamline $(\Delta E / E$ $=5 \times 10^{-2}$ ) which primarily results in reflections being fully recorded.

Primary radiation damage occurs on time scales of $100 \mathrm{fs}$. Thus, the 100 ps pulse duration at the APS is not fast enough to outrun primary radiation damage as can be done at XFELs. Secondary radiation damage from free radicals diffusing in the crystal and surrounding medium is thought to occur on time scales between microseconds and nanoseconds. The $100 \mathrm{ps}$ pulse is sufficiently short to outrun secondary damage in a single-shot experiment. In these experiments, in order to increase the intensity per exposure the intensity from several (4-24) bunches were accumulated on a single detector frame. The longer the exposure the more likely secondary radiation damage is to be observed. However, for these experiments the total dose and exposure duration were sufficiently low that site-specific radiation damage was not observed. Our singleshot data-collection protocol does not allow us to assess the effects of global damage.

The first pink-beam SX experiment was performed using crystals delivered by a fixed-target method (Meents et al., 2017). Data were collected with a single 100 ps X-ray pulse exposure per crystal in the APS hybrid mode. Each pulse delivered about $3 \times 10^{10}$ photons to the sample. Highresolution structures of $\mathrm{PC}$ and $\mathrm{PK}$ were determined from microcrystals between 20 and $40 \mu \mathrm{m}$ in size, which is similar to or larger than the beam size $[20 \times 20 \mu \mathrm{m}(H \times V)$, FWHM] used in their study. Here, we not only explored the minimum crystal size required to collect a complete data set at BioCARS, but also used an LCP injector with the pink beam, confirming that despite the higher background caused by X-ray scattering from the LCP crystal carrier, data of very good quality can be obtained. To this end, different scenarios of data collection by increasing the number of pulses from 1 to 24 were explored using $\mathrm{A}_{2 \mathrm{~A}} \mathrm{AR}$ as a pilot protein with a crystal size as small as $5 \mu \mathrm{m}$. We observed very low resolution $(\sim 10 \AA)$ and weak diffraction from $\mathrm{A}_{2 \mathrm{~A}} \mathrm{AR}$ microcrystals using one pulse $\left(7.5 \times 10^{9}\right.$ photons $)$ corresponding to an exposure time of $100 \mathrm{ps}$. These crystals were observed to diffract to 5-7 $\AA$ when the number of pulses was increased to four. However, the number of pulses had to be increased to 24 to be able to collect a $4.2 \AA$ resolution data set from such small and weakly diffracting crystals.

It is well known that radiation damage can represent a serious problem when collecting data on small crystals when using synchrotron radiation sources. However, use of the SX technique, in which crystals are replenished sufficiently quickly using new sample-delivery methods (such as the highviscosity injector), has demonstrated that the effects of radiation damage can be reduced significantly even when measuring microcrystals at room temperature with a mono- 
chromatic beam (Beyerlein et al., 2017; Botha et al., 2015; Gati et al., 2014; Hasegawa et al., 2017; Heymann et al., 2014; Huang et al., 2016, 2015; Martin-Garcia et al., 2017; Meents et al., 2017; Murray et al., 2015; Nogly et al., 2015; Stellato et al., 2014; Weinert et al., 2017; Zander et al., 2015). In a recent publication on radiation damage (Coquelle et al., 2015), the disulfide bridges of lysozyme were observed to be damaged by radiation when data sets were collected using a raster-scanning method and much higher doses (3.2 and 29.1 MGy) compared with the theoretical safe dose $(0.3 \mathrm{MGy}$; Nave \& Garman, 2005). In our study, the structures of $P K$ and $A_{2 A} A R$ were determined using 4 and 24 consecutive pulses, respectively, in which the number of photons delivered was $3 \times 10^{10}$ for the 4pulse structure, and $1.82 \times 10^{11}$ for the 24-pulse structure. The absence of visible radiation damage in our structures is consistent with the average absorbed radiation dose being significantly lower (Table 1) than the theoretical safe dose (Nave \& Garman, 2005). Thus, we have demonstrated that the pink X-ray beam SX method described here enables data collection and structure determination from microcrystals at room temperature with non-observable site-specific radiation damage.

Observing biological macromolecules in action at atomic resolution has been the holy grail for structural biologists since the first high-resolution structure of a protein was solved (Blake et al., 1965). The major challenge in the field of timeresolved X-ray crystallography has been the study of irreversible reactions, which can be initiated, for instance, by a flash of light or by diffusion of a substrate into the crystal lattice of a macromolecule. With the advent of XFELs this is now feasible (Martin-Garcia et al., 2016). It has recently been demonstrated that the binding of an antibiotic to an enzyme can be studied by collecting data at room temperature using time-resolved SFX at LCLS (Kupitz et al., 2017; Olmos et al., 2018). Such studies have remained largely elusive at synchrotron sources because of X-ray radiation damage, the need for growing large single crystals, challenges with crystal replenishment and the difficulty in initiating reactions uniformly in macroscopic crystals. It has been estimated that diffusion of a substrate into microcrystals would take $\sim 1 \mathrm{~ms}$ for $5 \mu \mathrm{m}$ crystals and $15 \mathrm{~ms}$ for $15 \mu \mathrm{m}$ crystals (Schmidt, 2013). Thus, crystal sizes used in the study presented here $(10-15 \mu \mathrm{m}$ for PK and $\sim 5 \mu \mathrm{m}$ for $\mathrm{A}_{2 \mathrm{~A}} \mathrm{AR}$ ) are suitable candidates for time-resolved studies of ligand binding and enzyme catalysis with microsecond resolution at synchrotrons using the pink-beam SX approach. Our results also open new opportunities in the field of GPCRs and other membrane proteins for time-resolved studies of their intermediate states and functional mechanisms at a microsecond and nanosecond resolution. In addition to this, our experimental settings can be extended to other microfocus beamlines at synchrotron ring sources with pink X-ray beams.

\section{Conclusions and outlook}

Our results demonstrate for the first time the feasibility of using a polychromatic or pink X-ray beam to collect single snapshots from randomly oriented micrometre-sized crystals delivered by a viscous media injector. In similar or equal conditions of crystal quality, size and concentration, by using a broader energy bandwidth of $5 \%$ at BioCARS, a much smaller number of diffraction patterns were required to assemble a complete data set compared with monochromatic radiation, which dramatically reduces the amount of sample required for structure determination. However, the $5 \%$ bandwidth is probably too wide. The ideal bandwidth is probably slightly wider than that required to record full reflections of optimal SNR without rotating the crystal in the X-ray beam.

Although the processing of pseudo-Laue data using MOSFLM and CrystFEL has limitations, we were, nevertheless, able to build a model of $\mathrm{A}_{2 \mathrm{~A}} \mathrm{AR}$ at $4.2 \AA$. This work therefore serves as a foundation for the development of software tools specifically for processing weak pseudo-Laue diffraction data, which could not be processed by Precognition.

The upcoming APS upgrade (and upgrades of other thirdgeneration synchrotrons), which will bring a smaller and brighter micro-focused beam $(0.5 \mu \mathrm{m}$ circular beam at monochromatic beamlines such as GM/CA, and $<10 \mu \mathrm{m}$ to a few micrometres at BioCARS) with up to two orders of magnitude higher average flux density along with new developments in beamline optics and the acquisition of faster frame-readout detectors, should enable $\mathrm{X}$-ray structure determination and time-resolved experiments at room temperature by reducing the exposure times. Furthermore, the new upgrades will improve the SNR, which has always been an obstacle in Laue crystallography, reducing the achievable resolution so that serial crystallography experiments from microcrystals as small as $1 \mu \mathrm{m}$ should also be possible.

Finally, the pink-beam mode would offer a clear opportunity to expand this methodology to XFELs (Dejoie et al., 2013). The combination of the extraordinary properties of XFELs, which offer exceptionally brilliant, microfocused $\mathrm{X}$-ray pulses, a few femtoseconds in duration, with a high repetition rate and full spatial coherence, along with a broader energy bandwidth, could have an enormous impact in the field of serial femtosecond crystallography especially in timeresolved studies (also referred to as 'molecular movies').

\section{Materials and methods}

\subsection{Sample preparation}

Microcrystals of $\mathrm{A}_{2 \mathrm{~A}} \mathrm{AR}$ and $\mathrm{PK}$ were prepared as previously described (Martin-Garcia et al., 2017). Crystals of $\mathrm{A}_{2 \mathrm{~A}} \mathrm{AR}$ were obtained in the home laboratory and shipped inside syringes to APS using temperature-controlled containers. Crystallization of PK was carried out onsite at the experimental laboratory of the BioCARS beamline 14-ID-B. Crystal size varied between $5 \times 5 \times 2 \mu \mathrm{m}$ for $\mathrm{A}_{2 \mathrm{~A}} \mathrm{AR}$ and $15 \times$ $10 \times 5 \mu \mathrm{m}$ for PK (Table 1). For PK the crystal density was adjusted before mixing them with LCP so that mainly singlecrystal hits were observed. The crystal mixtures were loaded directly from the Hamilton syringe into an LCP injector sample reservoir. 
5.2. Experimental set-up and serial data collection at the BioCARS 14-ID-B beamline

Serial data collection was performed at the BioCARS beamline (14-ID-B) at the APS at Argonne National Laboratory (Chicago, Illinois). A detailed description of the BioCARS beamline source can be found in Graber et al. (2011). The source consists of two in-line undulators with periods of 23 and $27 \mathrm{~mm}$ that together provide high-flux pinkbeam capability at $12 \mathrm{keV}$ as well as first-harmonic coverage from 6.8 to $19 \mathrm{keV}$. The isolation of single X-ray pulses is accomplished by using a combination of two high-speed X-ray choppers and a millisecond shutter. The choppers rotate continuously and modulate (or chop) the beam in time while the shutter is triggered to open on demand and transmit a single X-ray burst (one bunch or multiple bunches) to the sample. Each high-speed chopper is precisely synchronized with the storage-ring master radio-frequency clock at $351.93 \mathrm{MHz}$ being able to isolate single X-ray pulses at $1 \mathrm{kHz}$ in both hybrid and 24-bunch modes of the APS storage ring. In hybrid mode, each isolated X-ray pulse delivers up to $\sim 3 \times$ $10^{10}$ photons to the sample.

Microcrystals in a carrier LCP medium were injected into the intersection with the X-ray pink beam by using the viscous LCP injector (Weierstall et al., 2014) with a $50 \mu \mathrm{m}$ inner diameter fused silica capillary ('nozzle'). This nozzle size was chosen to avoid shearing and breaking up of the crystals during injection, nozzle clogging, as well as to minimize the background scattering from crystal carrier streams. For all our experiments, a $20 \mu \mathrm{l}$ reservoir was used. The experimental setup during our experiment at BioCARS beamline 14-ID-B is represented in Fig. 1. The LCP injector was mounted similarly to that used in our previous monochromatic experiment at GM/CA (Martin-Garcia et al., 2017).

During our experiment, the APS storage ring was operating in the standard 24-bunch mode in which 24 pulses circulate with $4.25 \mathrm{~mA}$ per pulse and $153 \mathrm{~ns}$ separation between pulses. Each pulse has a duration of 100 ps (FWHM) and delivers about $7.5 \times 10^{9}$ photons to the sample at a peak energy of $12 \mathrm{keV}$. The number of pulses to be used can be selected and isolated on demand from just one single pulse up to 24 consecutive pulses. The number of pulses in our measurements were from 1 to 24 consecutive pulses so that the number of photons delivered to the sample varied from $7.5 \times 10^{9}$ to 1.82 $\times 10^{11}$, and the exposure varied from $100 \mathrm{ps}$ to $3.53 \mu \mathrm{s}$. We used the minimum X-ray beam spot size currently achievable at BioCARS $25 \times 15 \mu \mathrm{m}(H \times V)(\mathrm{FWHM})$. Two high-resolution microscope CCD cameras were used to allow for the jet centering. Diffracted X-rays were recorded on a RAYONIX MX340HS CCD detector in the standard $2 \times 2$ binning mode (acquisition rate of $10 \mathrm{~Hz}$ ).

The average radiation dose (per crystal) was calculated using the RADDOSE-3D server (Zeldin, Brockhauser et al., 2013; Zeldin, Gerstel \& Garman et al., 2013), assuming crystals of dimensions $5 \times 5 \times 2 \mu \mathrm{m}$ for $\mathrm{A}_{2 \mathrm{~A}} \mathrm{AR}$ and $15 \times 10 \times 5 \mu \mathrm{m}$ for PK, a $25 \times 15 \mu \mathrm{m}(H \times V)(\mathrm{FWHM})$ beam size, a photon flux of $5.2 \times 10^{16}$ photons s$^{-1}$, an energy of $12 \mathrm{keV}$, and exposure times of $460 \mathrm{~ns}$ for $\mathrm{PK}$ and $3.53 \mu$ s for $\mathrm{A}_{2 \mathrm{~A}} \mathrm{AR}$. The results of this analysis are summarized in Table 1.

\subsection{Data reduction and analysis of serial Laue crystal- \\ lography}

Laue diffraction data for PK were processed using Precognition/Epinorm software packages (Renz Research Inc.) and the BioCARS python script pyPrecognition was used to automate processing of serial data. The script identifies socalled 'hits': images that potentially contain diffraction patterns. The criteria used for selecting hits were: more than 50 peaks detected with more than 30 counts above the background. Each hit was indexed separately using known roomtemperature cell parameters and space group. Geometry was then refined for each image, including cell parameters. A total of 30000 frames were recorded, of which 946 were identified as hits, and 715 images were reported by the program as 'indexed'. However, on inspection, some of these images were mis-indexed or they were multiple-crystal diffraction patterns and were excluded from further analysis so that only 626 images were processed: integrated to $1.8 \AA$ (using the analytical profile-fitting option in Precognition), scaled and merged using an $I / \sigma(I)$ of 3 as the cut-off (Table 2). Additionally, a data set composed of only the best 132 images out of the original 626 images (based on a large number of integrated spots, $>800$ ) was scaled and merged using an $I / \sigma(I)$ of 3 as the cut-off. This data set illustrates that far fewer images than 626 were sufficient to build a high-quality data set. This was the data set selected for further analysis of the structure of PK and is shown in Table 1. Statistics for merging at $I / \sigma(I)$ of 3 for this 132-image data set are also shown in Table 2, together with merging at lower $I / \sigma(I)$ cut-offs for comparison $(1.0,1.5$ and 2.0). The completeness as a function of the resolution for the 132-image data set is shown in Fig. S4 at different values of the $I / \sigma(I)$ cut-off.

Laue diffraction data of $\mathrm{A}_{2 \mathrm{~A}} \mathrm{AR}$ was processed using the standard analysis toolkit CrystFEL (White et al., 2012, 2013, 2016). The data reduction and analysis of the SX data mainly includes hit finding, indexing and intensity integration. Hit finding was conducted as the first step for data reduction to filter out only the actual crystal diffraction images from the blank ones. The hits were then indexed using indexamajig from CrystFEL (version 0.6.3; White et al., 2012, 2013, 2016) calling auto-indexing module MOSFLM (Powell et al., 2013). Given that the X-ray beam bandwidth is relatively small and the patterns are sparse (about 20 peaks per pattern), the majority of the observed spots were almost certainly sampled by the peak in the wavelength spectrum, hence indexing usually yielded satisfactory lattice constants. Using the geometry diffraction model for monochromatic indexing, the Miller indices were calculated and assigned to the reflections/ peaks that were found in the hit-finding stage. A pattern was only used if more than $50 \%$ of its spots overlapped with the prediction. Reflections were merged only if they were observed three or more times. Because the patterns were sparse, most peaks were sampled by the central wavelength, 
hence wavelength scaling prior to reflection merging was bypassed. A detailed description of the reflection-merging process and a subset of indexed patterns showing found and predicted peaks (Figs. S5 and S6) can be found in the Supporting information. Fig. S5 shows, for 64 indexed patterns, the found spots (blue circles) along with the predicted reflections (orange squares), as well as the resolution cut-off ( $4.2 \AA$, green circle). Fig. S6 shows a representative from the 771 indexed patterns. More representative indexed patterns can be found in the Supporting information.

\subsection{Model building and structure refinement}

MTZ files for phasing and refinement were generated by the CTRUNCATE program (Padilla \& Yeates, 2003) from the $C C P 4$ software package (Winn et al., 2011). Initial phases were obtained by molecular replacement with MOLREP (Vagin \& Teplyakov, 1997) using known structures of the proteins from the PDB. The PDB entries used in our study were 5uvi and 5uvl for $\mathrm{A}_{2 \mathrm{~A}} \mathrm{AR}$ and $\mathrm{PK}$, respectively (Martin-Garcia et al., 2017). Water molecules and ligands were removed from the reference structures for the phasing step. Structure refinement was carried out through multiple iterations of REFMAC5 (Murshudov et al., 2011) and phenix.refine (Winn et al., 2011; for $\mathrm{A}_{2 \mathrm{~A}} \mathrm{AR}$ ) to refine atomic coordinates and isotropic $B$ factors. Final refinement of $\mathrm{A}_{2 \mathrm{~A}} \mathrm{AR}$ was also performed with REFMAC5. Manual inspection of the structures was carried out using Coot (Emsley \& Cowtan, 2004) after each refinement step. The figures were prepared with PyMOL (version 1.8, Schrödinger LLC). Data-refinement statistics for all structures solved in this study are summarized in Table 1. Electron-density and composite OMIT maps were calculated with the MAPS tool in the PHENIX software suite (Adams $e t$ al., 2010). Validation of all structures was carried out with the validation tools in the PHENIX software suite (Adams et al., 2010).

\section{Acknowledgements}

We thank Vukica Šrajer (BioCARS) for processing PK data with Precognition, for discussions regarding Laue data processing and for carefully checking the manuscript before submission. Author contributions: J. M. Martin-Garcia, W. Liu, R. F. Fischetti, V. Cherezov, P. Fromme and J. C. H. Spence designed the experiments. R. F. Fischetti, U. Weierstall, R. Henning, H. Hu, G. Subramanian and S. Zhang designed and built the experimental setup. J. M. Martin-Garcia, A. Ishchenko, L. Zhu, H. Hu, G. Subramanian and S. Zhang grew crystals and prepared samples for data collection. J. M. Martin-Garcia, W. Liu, V. Cherezov, L. Zhu, U. Weierstall, R. F. Fischetti, R. Henning, H. Hu, G. Subramanian, S. Zhang, Z. Dobson, D. Kissick and C. Ogata participated in data collection. D. Mendez, C. Li, N. A. Zatsepin, J. M. Martin-Garcia, Ming-Yue Lee and D. Kissick analyzed the data. J. M. MartinGarcia prepared the figures for the article. J. M. MartinGarcia, W. Liu, V. Cherezov, R. F. Fischetti, Ming-Yue Lee and L. Zhu wrote the article with contributions from all authors. All authors read and approved the final manuscript.

\section{Funding information}

This work was supported by the Centre for Applied Structural Discovery at the Biodesign Institute at Arizona State University (W. Liu, P. Fromme, U. Weierstall, J. C. H. Spence, J. M. Martin-Garcia, N. A. Zatsepin, L. Zhu, M.-Y. Lee, E. Chun, G. Subramanian), a Mayo Clinic ASU Collaborative Seed Grant Award (W. Liu), the Flinn Foundation Seed Grant (W. Liu) and No. 1991 (P. Fromme, J. C. H. Spence, and J. M. Martin-Garcia), the STC Program of the National Science Foundation through BioXFEL (No. 1231306; W. Liu, P. Fromme, U. Weierstall, J. C. H. Spence, N. A. Zatsepin, D. Mendez, C. Li, G. Subramanian), National Science Foundation BIO ABI grant No. 1565180 (N. A. Zatsepin, D. Mendez, U. Weierstall, and J. C. H. Spence), and the National Institutes of Health (NIH) grants R21DA042298 (W. Liu), R01GM124152 (W. Liu), R01GM095583 (P. Fromme) and R35GM127086 (V. Cherezov and A. Ishchenko). Use of BioCARS was supported by the National Institute of General Medical Sciences of the National Institutes of Health under grant number R24GM111072. Time-resolved setup at sector 14 was funded in part through a collaboration with Philip Anfinrud (NIH/ NIDDK). Use of the GM/CA at the Advanced Photon Source, Argonne National Laboratory was supported by the National Cancer Institute (ACB-12002; R. F. Fischetti, D. Kissick, and C. Ogata) and the National Institute of General Medical Sciences (AGM12006; R. F. Fischetti, D. Kissick, and C. Ogata). Use of the Advanced Photon Source, a US Department of Energy (DOE) Office of Science User Facility operated for the DOE Office of Science by Argonne National Laboratory, was supported under Contract No. DE-AC0206 CH11357.

\section{References}

Adams, P. D., Afonine, P. V., Bunkóczi, G., Chen, V. B., Davis, I. W., Echols, N., Headd, J. J., Hung, L.-W., Kapral, G. J., GrosseKunstleve, R. W., McCoy, A. J., Moriarty, N. W., Oeffner, R., Read, R. J., Richardson, D. C., Richardson, J. S., Terwilliger, T. C. \& Zwart, P. H. (2010). Acta Cryst. D66, 213-221.

Ayvazyan, V., Baboi, N., Bähr, J., Balandin, V., Beutner, B., Brandt, A., Bohnet, I., Bolzmann, A., Brinkmann, R., Brovko, O. I., Carneiro, J. P., Casalbuoni, S., Castellano, M., Castro, P., Catani, L., Chiadroni, E., Choroba, S., Cianchi, A., Delsim-Hashemi, H., Di Pirro, G., Dohlus, M., Düsterer, S., Edwards, H. T., Faatz, B., Fateev, A. A., Feldhaus, J., Flöttmann, K., Frisch, J., Fröhlich, L., Garvey, T., Gensch, U., Golubeva, N., Grabosch, H.-J., Grigoryan, B., Grimm, O., Hahn, U., Han, J. H., Hartrott, M. V., Honkavaara, K., Hüning, M., Ischebeck, R., Jaeschke, E., Jablonka, M., Kammering, R., Katalev, V., Keitel, B., Khodyachykh, S., Kim, Y., Kocharyan, V., Körfer, M., Kollewe, M., Kostin, D., Krämer, D., Krassilnikov, M., Kube, G., Lilje, L., Limberg, T., Lipka, D., Löhl, F., Luong, M., Magne, C., Menzel, J., Michelato, P., Miltchev, V., Minty, M., Möller, W. D., Monaco, L., Müller, W., Nagl, M., Napoly, O., Nicolosi, P., Nölle, D., Nuñez, T., Oppelt, A., Pagani, C., Paparella, R., Petersen, B., Petrosyan, B., Pflüger, J., Piot, P., Plönjes, E., Poletto, L., Proch, D., Pugachov, D., Rehlich, K., Richter, D., Riemann, S., Ross, M., Rossbach, J., Sachwitz, M., Saldin, E. L., Sandner, W., Schlarb, H., Schmidt, B., Schmitz, M., Schmüser, P., Schneider, J. R., Schneidmiller, E. A., Schreiber, H.-J., Schreiber, S., Shabunov, A. V., Sertore, D., Setzer, S., Simrock, S., Sombrowski, E., Staykov, L., Steffen, B., Stephan, F., Stulle, F., Sytchev, K. P., Thom, H., Tiedtke, 
K., Tischer, M., Treusch, R., Trines, D., Tsakov, I., Vardanyan, A., Wanzenberg, R., Weiland, T., Weise, H., Wendt, M., Will, I., Winter, A., Wittenburg, K., Yurkov, M. V., Zagorodnov, I., Zambolin, P. \& Zapfe, K. (2006). Eur. Phys. J. D, 37, 297-303.

Batyuk, A., Galli, L., Ishchenko, A., Han, G. W., Gati, C., Popov, P. A., Lee, M. Y., Stauch, B., White, T. A., Barty, A., Aquila, A., Hunter, M. S., Liang, M., Boutet, S., Pu, M., Liu, Z. J., Nelson, G., James, D., Li, C., Zhao, Y., Spence, J. C., Liu, W., Fromme, P., Katritch, V., Weierstall, U., Stevens, R. C. \& Cherezov, V. (2016). Sci. Adv. 2, e1600292.

Betzel, Ch., Pal, G. P. \& Saenger, W. (1988). Acta Cryst. B44, 163-172. Beyerlein, K. R., Dierksmeyer, D., Mariani, V., Kuhn, M., Sarrou, I., Ottaviano, A., Awel, S., Knoska, J., Fuglerud, S., Jönsson, O., Stern, S., Wiedorn, M. O., Yefanov, O., Adriano, L., Bean, R., Burkhardt, A., Fischer, P., Heymann, M., Horke, D. A., Jungnickel, K. E. J., Kovaleva, E., Lorbeer, O., Metz, M., Meyer, J., Morgan, A., Pande, K., Panneerselvam, S., Seuring, C., Tolstikova, A., Lieske, J., Aplin, S., Roessle, M., White, T. A., Chapman, H. N., Meents, A. \& Oberthuer, D. (2017). IUCrJ, 4, 769-777.

Blake, C. C., Koenig, D. F., Mair, G. A., North, A. C., Phillips, D. C. \& Sarma, V. R. (1965). Nature, 206, 757-761.

Bolduc, J. M., Dyer, D. H., Scott, W. G., Singer, P., Sweet, R. M., Koshland, D. E. Jr \& Stoddard, B. L. (1995). Science, 268, 13121318.

Botha, S., Nass, K., Barends, T. R. M., Kabsch, W., Latz, B., Dworkowski, F., Foucar, L., Panepucci, E., Wang, M., Shoeman, R. L., Schlichting, I. \& Doak, R. B. (2015). Acta Cryst. D71, 387-397.

Bourgeois, D. \& Royant, A. (2005). Curr. Opin. Struct. Biol. 15, 538547.

Bourgeois, D., Ursby, T., Wulff, M., Pradervand, C., Legrand, A., Schildkamp, W., Labouré, S., Srajer, V., Teng, T. Y., Roth, M. \& Moffat, K. (1996). J. Synchrotron Rad. 3, 65-74.

Bourgeois, D., Vallone, B., Schotte, F., Arcovito, A., Miele, A. E., Sciara, G., Wulff, M., Anfinrud, P. \& Brunori, M. (2003). Proc. Natl Acad. Sci. USA, 100, 8704-8709.

Chapman, H. N., Fromme, P., Barty, A., White, T. A., Kirian, R. A., Aquila, A., Hunter, M. S., Schulz, J., DePonte, D. P., Weierstall, U., Doak, R. B., Maia, F. R., Martin, A. V., Schlichting, I., Lomb, L., Coppola, N., Shoeman, R. L., Epp, S. W., Hartmann, R., Rolles, D., Rudenko, A., Foucar, L., Kimmel, N., Weidenspointner, G., Holl, P., Liang, M., Barthelmess, M., Caleman, C., Boutet, S., Bogan, M. J., Krzywinski, J., Bostedt, C., Bajt, S., Gumprecht, L., Rudek, B., Erk, B., Schmidt, C., Hömke, A., Reich, C., Pietschner, D., Strüder, L., Hauser, G., Gorke, H., Ullrich, J., Herrmann, S., Schaller, G., Schopper, F., Soltau, H., Kühnel, K. U., Messerschmidt, M., Bozek, J. D., Hau-Riege, S. P., Frank, M., Hampton, C. Y., Sierra, R. G., Starodub, D., Williams, G. J., Hajdu, J., Timneanu, N., Seibert, M. M., Andreasson, J., Rocker, A., Jönsson, O., Svenda, M., Stern, S., Nass, K., Andritschke, R., Schröter, C. D., Krasniqi, F., Bott, M., Schmidt, K. E., Wang, X., Grotjohann, I., Holton, J. M., Barends, T. R., Neutze, R., Marchesini, S., Fromme, R., Schorb, S., Rupp, D., Adolph, M., Gorkhover, T., Andersson, I., Hirsemann, H., Potdevin, G., Graafsma, H., Nilsson, B. \& Spence, J. C. (2011). Nature, 470, 73-77.

Coquelle, N., Brewster, A. S., Kapp, U., Shilova, A., Weinhausen, B., Burghammer,M.\& Colletier,J.-P.(2015).Acta Cryst. D71, 1184-1196.

Dejoie, C., McCusker, L. B., Baerlocher, C., Abela, R., Patterson, B. D., Kunz, M. \& Tamura, N. (2013). J. Appl. Cryst. 46, 791-794.

Emsley, P. \& Cowtan, K. (2004). Acta Cryst. D60, 2126-2132.

Feld, G. K., Heymann, M., Benner, W. H., Pardini, T., Tsai, C.-J., Boutet, S., Coleman, M. A., Hunter, M. S., Li, X., Messerschmidt, M., Opathalage, A., Pedrini, B., Williams, G. J., Krantz, B. A., Fraden, S., Hau-Riege, S., Evans, J. E., Segelke, B. W. \& Frank, M. (2015). J. Appl. Cryst. 48, 1072-1079.

Fülöp, V., Phizackerley, R. P., Soltis, S. M., Clifton, I. J., Wakatsuki, S., Erman, J., Hajdu, J. \& Edwards, S. L. (1994). Structure, 2, 201-208.

Gati, C., Bourenkov, G., Klinge, M., Rehders, D., Stellato, F., Oberthür, D., Yefanov, O., Sommer, B. P., Mogk, S., Duszenko,
M., Betzel, C., Schneider, T. R., Chapman, H. N. \& Redecke, L. (2014). IUCrJ, 1, 87-94.

Genick, U. K., Borgstahl, G. E., Ng, K., Ren, Z., Pradervand, C., Burke, P. M., Srajer, V., Teng, T. Y., Schildkamp, W., McRee, D. E., Moffat, K. \& Getzoff, E. D. (1997). Science, 275, 1471-1475.

Graber, T., Anderson, S., Brewer, H., Chen, Y.-S., Cho, H. S., Dashdorj, N., Henning, R. W., Kosheleva, I., Macha, G., Meron, M., Pahl, R., Ren, Z., Ruan, S., Schotte, F., Srajer, V., Viccaro, P. J., Westferro, F., Anfinrud, P. \& Moffat, K. (2011). J. Synchrotron Rad. 18, 658-670.

Hajdu, J. \& Johnson, L. N. (1990). Biochemistry, 29, 1669-1678.

Hajdu, J., Machin, P. A., Campbell, J. W., Greenhough, T. J., Clifton, I. J., Zurek, S., Gover, S., Johnson, L. N. \& Elder, M. (1987). Nature, 329, 178-181.

Hasegawa, K., Yamashita, K., Murai, T., Nuemket, N., Hirata, K., Ueno, G., Ago, H., Nakatsu, T., Kumasaka, T. \& Yamamoto, M. (2017). J. Synchrotron Rad. 24, 29-41.

Heymann, M., Opthalage, A., Wierman, J. L., Akella, S., Szebenyi, D. M. E., Gruner, S. M. \& Fraden, S. (2014). IUCrJ, 1, 349-360.

Huang, C.-Y., Olieric, V., Ma, P., Howe, N., Vogeley, L., Liu, X., Warshamanage, R., Weinert, T., Panepucci, E., Kobilka, B., Diederichs, K., Wang, M. \& Caffrey, M. (2016). Acta Cryst. D72, 93-112.

Huang, C.-Y., Olieric, V., Ma, P., Panepucci, E., Diederichs, K., Wang, M. \& Caffrey, M. (2015). Acta Cryst. D71, 1238-1256.

Ihee, H., Rajagopal, S., Srajer, V., Pahl, R., Anderson, S., Schmidt, M., Schotte, F., Anfinrud, P. A., Wulff, M. \& Moffat, K. (2005). Proc. Natl Acad. Sci. USA, 102, 7145-7150.

Knapp, J. E., Pahl, R., Srajer, V. \& Royer, W. E. Jr (2006). Proc. Natl Acad. Sci. USA, 103, 7649-7654.

Kupitz, C., Basu, S., Grotjohann, I., Fromme, R., Zatsepin, N. A., Rendek, K. N., Hunter, M. S., Shoeman, R. L., White, T. A., Wang, D., James, D., Yang, J. H., Cobb, D. E., Reeder, B., Sierra, R. G., Liu, H., Barty, A., Aquila, A. L., Deponte, D., Kirian, R. A., Bari, S., Bergkamp, J. J., Beyerlein, K. R., Bogan, M. J., Caleman, C., Chao, T. C., Conrad, C. E., Davis, K. M., Fleckenstein, H., Galli, L., HauRiege, S. P., Kassemeyer, S., Laksmono, H., Liang, M., Lomb, L., Marchesini, S., Martin, A. V., Messerschmidt, M., Milathianaki, D., Nass, K., Ros, A., Roy-Chowdhury, S., Schmidt, K., Seibert, M., Steinbrener, J., Stellato, F., Yan, L., Yoon, C., Moore, T. A., Moore, A. L., Pushkar, Y., Williams, G. J., Boutet, S., Doak, R. B., Weierstall, U., Frank, M., Chapman, H. N., Spence, J. C. \& Fromme, P. (2014). Nature, 513, 261-265.

Kupitz, C., Olmos, J. L. Jr, Holl, M., Tremblay, L., Pande, K., Pandey, S., Oberthür, D., Hunter, M., Liang, M., Aquila, A., Tenboer, J., Calvey, G., Katz, A., Chen, Y., Wiedorn, M. O., Knoska, J., Meents, A., Majriani, V., Norwood, T., Poudyal, I., Grant, T., Miller, M. D., Xu, W., Tolstikova, A., Morgan, A., Metz, M., Martin-Garcia, J. M., Zook, J. D., Roy-Chowdhury, S., Coe, J., Nagaratnam, N., Meza, D., Fromme, R., Basu, S., Frank, M., White, T., Barty, A., Bajt, S., Yefanov, O., Chapman, H. N., Zatsepin, N., Nelson, G., Weierstall, U., Spence, J., Schwander, P., Pollack, L., Fromme, P., Ourmazd, A., Phillips, G. N. Jr \& Schmidt, M. (2017). Struct. Dyn. 4, 044003.

Liu, W., Chun, E., Thompson, A. A., Chubukov, P., Xu, F., Katritch, V., Han, G. W., Roth, C. B., Heitman, L. H., IJzerman, A. P., Cherezov, V. \& Stevens, R. C. (2012). Science, 337, 232-236.

Martin-Garcia, J. M., Conrad, C. E., Coe, J., Roy-Chowdhury, S. \& Fromme, P. (2016). Arch. Biochem. Biophys. 602, 32-47.

Martin-Garcia, J. M., Conrad, C. E., Nelson, G., Stander, N., Zatsepin, N. A., Zook, J., Zhu, L., Geiger, J., Chun, E., Kissick, D., Hilgart, M. C., Ogata, C., Ishchenko, A., Nagaratnam, N., Roy-Chowdhury, S., Coe, J., Subramanian, G., Schaffer, A., James, D., Ketwala, G., Venugopalan, N., Xu, S., Corcoran, S., Ferguson, D., Weierstall, U., Spence, J. C. H., Cherezov, V., Fromme, P., Fischetti, R. F. \& Liu, W. (2017). IUCrJ, 4, 439-454.

Meents, A., Wiedorn, M. O., Srajer, V., Henning, R., Sarrou, I., Bergtholdt, J., Barthelmess, M., Reinke, P. Y. A., Dierksmeyer, D., Tolstikova, A., Schaible, S., Messerschmidt, M., Ogata, C. M., 
Kissick, D. J., Taft, M. H., Manstein, D. J., Lieske, J., Oberthuer, D., Fischetti, R. F. \& Chapman, H. N. (2017). Nat. Commun. 8, 1281.

Mizohata, E., Nakane, T., Fukuda, Y., Nango, E. \& Iwata, S. (2018). Biophys. Rev. 10, 209-218.

Moffat, K. (1998). Acta Cryst. A54, 833-841.

Moffat, K., Szebenyi, D. \& Bilderback, D. (1984). Science, 223, $1423-$ 1425.

Murray, T. D., Lyubimov, A. Y., Ogata, C. M., Vo, H., Uervirojnangkoorn, M., Brunger, A. T. \& Berger, J. M. (2015). Acta Cryst. D71, 1987-1997.

Murshudov, G. N., Skubák, P., Lebedev, A. A., Pannu, N. S., Steiner, R. A., Nicholls, R. A., Winn, M. D., Long, F. \& Vagin, A. A. (2011). Acta Cryst. D67, 355-367.

Nave, C. \& Garman, E. F. (2005). J. Synchrotron Rad. 12, 257260.

Neutze, R. \& Moffat, K. (2012). Curr. Opin. Struct. Biol. 22, 651659.

Nogly, P., James, D., Wang, D., White, T. A., Zatsepin, N., Shilova, A., Nelson, G., Liu, H., Johansson, L., Heymann, M., Jaeger, K., Metz, M., Wickstrand, C., Wu, W., Båth, P., Berntsen, P., Oberthuer, D., Panneels, V., Cherezov, V., Chapman, H., Schertler, G., Neutze, R., Spence, J., Moraes, I., Burghammer, M., Standfuss, J. \& Weierstall, U. (2015). IUCrJ, 2, 168-176.

Nozawa, S., Adachi, S., Takahashi, J., Tazaki, R., Guérin, L., Daimon, M., Tomita, A., Sato, T., Chollet, M., Collet, E., Cailleau, H., Yamamoto, S., Tsuchiya, K., Shioya, T., Sasaki, H., Mori, T., Ichiyanagi, K., Sawa, H., Kawata, H. \& Koshihara, S. (2007). J. Synchrotron Rad. 14, 313-319.

Olmos, J. L. Jr, Pandey, S., Martin-Garcia, J. M., Calvey, G., Katz, A., Knoska, J., Kupitz, C., Hunter, M. S., Liang, M., Oberthuer, D., Yefanov, O., Wiedorn, M., Heyman, M., Holl, M., Pande, K., Barty, A., Miller, M. D., Stern, S., Roy-Chowdhury, S., Coe, J., Nagaratnam, N., Zook, J., Verburgt, J., Norwood, T., Poudyal, I., Xu, D., Koglin, J., Seaberg, M., Zhao, Y., Bajt, S., Grant, T., Mariani, V., Nelson, G., Subramanian, G., Bae, E., Fromme, R., Fung, R., Schwander, P., Frank, M., White, T. A., Weierstall, U., Zatsepin, N., Spence, J. C. H., Fromme, P., Chapman, H. N., Pollack, L., Tremblay, L., Ourmazd, O., Phillips, J. G. \& Schmidt, M. (2018). BMC Biol. 16, 59.

Owen, R. L., Axford, D., Nettleship, J. E., Owens, R. J., Robinson, J. I., Morgan, A. W., Doré, A. S., Lebon, G., Tate, C. G., Fry, E. E., Ren, J., Stuart, D. I. \& Evans, G. (2012). Acta Cryst. D68, 810-818. Padilla, J. E. \& Yeates, T. O. (2003). Acta Cryst. D59, 1124-1130.

Pande, K., Hutchison, C. D., Groenhof, G., Aquila, A., Robinson, J. S., Tenboer, J., Basu, S., Boutet, S., DePonte, D. P., Liang, M., White, T. A., Zatsepin, N. A., Yefanov, O., Morozov, D., Oberthuer, D., Gati, C., Subramanian, G., James, D., Zhao, Y., Koralek, J., Brayshaw, J., Kupitz, C., Conrad, C., Roy-Chowdhury, S., Coe, J. D., Metz, M., Xavier, P. L., Grant, T. D., Koglin, J. E., Ketawala, G., Fromme, R., rajer, V., Henning, R., Spence, J. C., Ourmazd, A., Schwander, P., Weierstall, U., Frank, M., Fromme, P., Barty, A., Chapman, H. N., Moffat, K., van Thor, J. J. \& Schmidt, M. (2016). Science, 352, 725 729.

Powell, H. R., Johnson, O. \& Leslie, A. G. W. (2013). Acta Cryst. D69, 1195-1203.

Ren, Z., Bourgeois, D., Helliwell, J. R., Moffat, K., Šrajer, V. \& Stoddard, B. L. (1999). J. Synchrotron Rad. 6, 891-917.

Ren, Z., Srajer, V., Knapp, J. E. \& Royer, W. E. Jr (2012). Proc. Natl Acad. Sci. USA, 109, 107-112.

Schlichting, I., Almo, S. C., Rapp, G., Wilson, K., Petratos, K., Lentfer, A., Wittinghofer, A., Kabsch, W., Pai, E. F., Petsko, G. A. \& Goody, R. S. (1990). Nature, 345, 309-315.

Schmidt, M. (2013). Adv. Condens. Matter Phys. 2013, 1-10.

Schmidt, M., Graber, T., Henning, R. \& Srajer, V. (2010). Acta Cryst. A66, 198-206.

Schmidt, M., Nienhaus, K., Pahl, R., Krasselt, A., Anderson, S., Parak, F., Nienhaus, G. U. \& Srajer, V. (2005). Proc. Natl Acad. Sci. USA, 102, 11704-11709.
Schotte, F., Lim, M., Jackson, T. A., Smirnov, A. V., Soman, J., Olson, J. S., Phillips, G. N. Jr, Wulff, M. \& Anfinrud, P. A. (2003). Science, 300, 1944-1947.

Schotte, F., Soman, J., Olson, J. S., Wulff, M. \& Anfinrud, P. A. (2004). J. Struct. Biol. 147, 235-246.

Sierra, R. G., Laksmono, H., Kern, J., Tran, R., Hattne, J., AlonsoMori, R., Lassalle-Kaiser, B., Glöckner, C., Hellmich, J., Schafer, D. W., Echols, N., Gildea, R. J., Grosse-Kunstleve, R. W., Sellberg, J., McQueen, T. A., Fry, A. R., Messerschmidt, M. M., Miahnahri, A., Seibert, M. M., Hampton, C. Y., Starodub, D., Loh, N. D., Sokaras, D., Weng, T.-C., Zwart, P. H., Glatzel, P., Milathianaki, D., White, W. E., Adams, P. D., Williams, G. J., Boutet, S., Zouni, A., Messinger, J., Sauter, N. K., Bergmann, U., Yano, J., Yachandra, V. K. \& Bogan, M. J. (2012). Acta Cryst. D68, 1584-1587.

Šrajer, V., Ren, Z., Teng, T. Y., Schmidt, M., Ursby, T., Bourgeois, D., Pradervand, C., Schildkamp, W., Wulff, M. \& Moffat, K. (2001). Biochemistry, 40, 13802-13815.

Šrajer, V. \& Schmidt, M. (2017). J. Phys. D Appl. Phys. 50

Stellato, F., Oberthür, D., Liang, M., Bean, R., Gati, C., Yefanov, O., Barty, A., Burkhardt, A., Fischer, P., Galli, L., Kirian, R. A., Meyer, J., Panneerselvam, S., Yoon, C. H., Chervinskii, F., Speller, E., White, T. A., Betzel, C., Meents, A. \& Chapman, H. N. (2014). IUCrJ, 1, 204-212.

Stoddard, B. L. (2001). Methods, 24, 125-138.

Stoddard, B. L., Cohen, B. E., Brubaker, M., Mesecar, A. D. \& Koshland, D. E. Jr (1998). Nat. Struct. Mol. Biol. 5, 891-897.

Tenboer, J., Basu, S., Zatsepin, N., Pande, K., Milathianaki, D., Frank, M., Hunter, M., Boutet, S., Williams, G. J., Koglin, J. E., Oberthuer, D., Heymann, M., Kupitz, C., Conrad, C., Coe, J., Roy-Chowdhury, S., Weierstall, U., James, D., Wang, D., Grant, T., Barty, A., Yefanov, O., Scales, J., Gati, C., Seuring, C., Srajer, V., Henning, R., Schwander, P., Fromme, R., Ourmazd, A., Moffat, K., Van Thor, J. J., Spence, J. C., Fromme, P., Chapman, H. N. \& Schmidt, M. (2014). Science, 346, 1242-1246.

Terwilliger, T. C., Grosse-Kunstleve, R. W., Afonine, P. V., Moriarty, N. W., Adams, P. D., Read, R. J., Zwart, P. H. \& Hung, L.-W. (2008). Acta Cryst. D64, 515-524.

Vagin, A. \& Teplyakov, A. (1997). J. Appl. Cryst. 30, 10221025.

Warkentin, M. A., Atakisi, H., Hopkins, J. B., Walko, D. \& Thorne, R. E. (2017). IUCrJ, 4, 785-794.

Warkentin, M., Hopkins, J. B., Badeau, R., Mulichak, A. M., Keefe, L. J. \& Thorne, R. E. (2013). J. Synchrotron Rad. 20, 7-13.

Weierstall, U., James, D., Wang, C., White, T. A., Wang, D., Liu, W., Spence, J. C., Bruce Doak, R., Nelson, G., Fromme, P., Fromme, R., Grotjohann, I., Kupitz, C., Zatsepin, N. A., Liu, H., Basu, S., Wacker, D., Won Han, G., Katritch, V., Boutet, S., Messerschmidt, M., Williams, G. J., Koglin, J. E., Marvin Seibert, M., Klinker, M., Gati, C., Shoeman, R. L., Barty, A., Chapman, H. N., Kirian, R. A., Beyerlein, K. R., Stevens, R. C., Li, D., Shah, S. T., Howe, N., Caffrey, M. \& Cherezov, V. (2014). Nat. Commun. 5, 3309.

Weierstall, U., Spence, J. C. \& Doak, R. B. (2012). Rev. Sci. Instrum. 83, 035108 .

Weinert, T., Olieric, N., Cheng, R., Brünle, S., James, D., Ozerov, D., Gashi, D., Vera, L., Marsh, M., Jaeger, K., Dworkowski, F., Panepucci, E., Basu, S., Skopintsev, P., Doré, A. S., Geng, T., Cooke, R. M., Liang, M., Prota, A. E., Panneels, V., Nogly, P., Ermler, U., Schertler, G., Hennig, M., Steinmetz, M. O., Wang, M. \& Standfuss, J. (2017). Nat. Commun. 8, 542.

White, T. A., Barty, A., Stellato, F., Holton, J. M., Kirian, R. A., Zatsepin, N. A. \& Chapman, H. N. (2013). Acta Cryst. D69, 12311240.

White, T. A., Kirian, R. A., Martin, A. V., Aquila, A., Nass, K., Barty, A. \& Chapman, H. N. (2012). J. Appl. Cryst. 45, 335-341.

White, T. A., Mariani, V., Brehm, W., Yefanov, O., Barty, A., Beyerlein, K. R., Chervinskii, F., Galli, L., Gati, C., Nakane, T., Tolstikova, A., Yamashita, K., Yoon, C. H., Diederichs, K. \& Chapman, H. N. (2016). J. Appl. Cryst. 49, 680-689. 
Winn, M. D., Ballard, C. C., Cowtan, K. D., Dodson, E. J., Emsley, P., Evans, P. R., Keegan, R. M., Krissinel, E. B., Leslie, A. G. W., McCoy, A., McNicholas, S. J., Murshudov, G. N., Pannu, N. S., Potterton, E. A., Powell, H. R., Read, R. J., Vagin, A. \& Wilson, K. S. (2011). Acta Cryst. D67, 235-242.

Wöhri, A. B., Katona, G., Johansson, L. C., Fritz, E., Malmerberg, E., Andersson, M., Vincent, J., Eklund, M., Cammarata, M., Wulff, M., Davidsson, J., Groenhof, G. \& Neutze, R. (2010). Science, 328, 630633.
Yazawa, K., Sugahara, M., Yutani, K., Takehira, M. \& Numata, K. (2016). ACS Catal. 6, 3036-3046.

Zander, U., Bourenkov, G., Popov, A. N., de Sanctis, D., Svensson, O., McCarthy, A. A., Round, E., Gordeliy, V., Mueller-Dieckmann, C. \& Leonard, G. A. (2015). Acta Cryst. D71, 2328-2343.

Zeldin, O. B., Brockhauser, S., Bremridge, J., Holton, J. M. \& Garman, E. F. (2013). Proc. Natl Acad. Sci. USA, 110, 20551-20556.

Zeldin, O. B., Gerstel, M. \& Garman, E. F. (2013). J. Synchrotron Rad. 20, 49-57. 